\title{
Article
}

\section{Trypsin Induced Degradation of Amyloid Fibrils}

\author{
Olga V. Stepanenko ${ }^{1}{ }^{(D)}$, Maksim I. Sulatsky ${ }^{2}$, Ekaterina V. Mikhailova ${ }^{1}$, Olesya V. Stepanenko ${ }^{1}$ (D), \\ Irina M. Kuznetsova ${ }^{1}$, Konstantin K. Turoverov ${ }^{1,3, * \mathbb{D}}$ and Anna I. Sulatskaya ${ }^{1}$ D
}

1 Laboratory of Structural Dynamics, Stability and Folding of Proteins, Institute of Cytology, Russian Academy of Sciences, 4 Tikhoretsky Avenue, 194064 St. Petersburg, Russia; sov@incras.ru (O.V.S.); 4evamkh@gmail.com (E.V.M.); lvs@incras.ru (O.V.S.); imk@incras.ru (I.M.K.); ansul@mail.ru (A.I.S.)

2 Laboratory of Cell Morphology, Institute of Cytology, Russian Academy of Sciences, 4 Tikhoretsky Avenue, 194064 St. Petersburg, Russia; m_sulatsky@mail.ru

3 Institute of Physics, Nanotechnology and Telecommunications, Peter the Great St. Petersburg Polytechnic University, Polytechnicheskaya 29, 195251 St. Petersburg, Russia

* Correspondence: kkt@incras.ru; Tel.: +7-812-297-19-57

Citation: Stepanenko, O.V.; Sulatsky, M.I.; Mikhailova, E.V.; Stepanenko, O.V.; Kuznetsova, I.M.; Turoverov, K.K.; Sulatskaya, A.I. Trypsin Induced Degradation of Amyloid Fibrils. Int. J. Mol. Sci. 2021, 22, 4828. https://doi.org/10.3390/ijms22094828

Academic Editor: Ludmilla

A. Morozova-Roche

Received: 1 April 2021

Accepted: 30 April 2021

Published: 2 May 2021

Publisher's Note: MDPI stays neutral with regard to jurisdictional claims in published maps and institutional affiliations.

Copyright: (c) 2021 by the authors. Licensee MDPI, Basel, Switzerland. This article is an open access article distributed under the terms and conditions of the Creative Commons Attribution (CC BY) license (https:/ / creativecommons.org/licenses/by/ $4.0 /)$.
Abstract: Proteolytic enzymes are known to be involved in the formation and degradation of various monomeric proteins, but the effect of proteases on the ordered protein aggregates, amyloid fibrils, which are considered to be extremely stable, remains poorly understood. In this work we study resistance to proteolytic degradation of lysozyme amyloid fibrils with two different types of morphology and beta-2-microglobulun amyloids. We showed that the proteolytic enzyme of the pancreas, trypsin, induced degradation of amyloid fibrils, and the mechanism of this process was qualitatively the same for all investigated amyloids. At the same time, we found a dependence of efficiency and rate of fibril degradation on the structure of the amyloid-forming protein as well as on the morphology and clustering of amyloid fibrils. It was assumed that the discovered relationship between fibrils structure and the efficiency of their degradation by trypsin can become the basis of a new express method for the analysis of amyloids polymorphism. Unexpectedly lower resistance of both types of lysozyme amyloids to trypsin exposure compared to the native monomeric protein (which is not susceptible to hydrolysis) was attributed to the higher availability of cleavage sites in studied fibrils. Another intriguing result of the work is that the cytotoxicity of amyloids treated with trypsin was not only failing to decline, but even increasing in the case of beta-2-microglobulin fibrils.

Keywords: amyloid fibrils; proteolytic degradation; trypsin; stability; fragmentation; cytotoxicity; florescent probes; thioflavin T (ThT); 1-anilinonaphthalene-8-sulphonate (ANS)

\section{Introduction}

The development of a number of serious diseases, so-called conformational diseases, which include Alzheimer's, Parkinson's, prion diseases, etc. [1-7], is associated with the accumulation of amyloid fibrils in various organs and tissues of the human body. The appearance of an amyloidogenic protein in the body may be due to the proteolytic cleavage of its precursor, which itself does not tend to aggregate to form amyloid fibrils [8-11]. For example, $\beta$-secretase generates several short peptides from the amyloid precursor protein (APP). The formation of amyloid fibrils from one of these peptides (42 amino acid residues long) is associated with Alzheimer's disease [8]. Thus, the processing of precursor proteins with the participation of proteolytic enzymes leads to the formation of native proteins and peptides [12], including those with amyloidogenic properties.

In addition, proteases can modify native proteins and induce, accelerate, slow down, or even inhibit their aggregation [13-15]. In particular, it was shown that the rate of whey protein concentrate (WPC) aggregation increases significantly upon treatment with trypsin and noticeably decreases upon treatment with protease A, pepsin, and protease M [13]. This indicates the possible involvement of proteolytic enzymes in the fibrillogenesis of 
various proteins. Recent studies also indicate that proteases, in particular trypsin, NETassociated elastase, proteinase K, and HTRA1, can lead to degradation of mature amyloid fibrils, including those accumulating in amyloid plaques in vivo [16-21]. This is probably due to the main function of proteolytic enzymes, which consists of the degradation of misfolded proteins [22-27]. Assessment of fibril resistance to proteolysis is currently used as an effective approach to the analysis of external factors influence on the structure and stability of amyloids [18]. However, despite the widespread use for the study of amyloids, the mechanisms of fibril degradation under the influence of proteases and changes in the structure and cytotoxicity of amyloids, induced by the treatment with these enzymes, remain poorly understood.

In this work, we investigated the process of degradation of amyloid fibrils formed from two amyloidogenic proteins with significantly different primary, secondary, and tertiary native structure after the action of the trypsin serine protease, which is widely used to estimate the resistance of fibrils to proteolysis. Trypsin is one of the main digestive enzymes and effectively catalyzes the hydrolytic cleavage of proteins and peptides at the carboxyl side of L-lysine or L-arginine residues. We revealed changes in the structure and stability of amyloid fibrils after the action of trypsin using a number of spectroscopic approaches, including fluorescence of the amyloid-specific dye thioflavin T (ThT) and the hydrophobic probe 1-anilinonaphthalene-8-sulfonic acid (ANS), as well as transmission electron microscopy (TEM) for amyloid fibrils imaging. The cytotoxicity of amyloid fibrils before and after trypsin exposure was evaluated using the HeLa cell line. Lysozyme and beta-2-microglobulin were chosen as amyloidogenic proteins in this study. Accumulation of amyloid fibrils of these proteins leads to the development of hereditary lysozyme systemic amyloidosis (ALys amyloidosis, [28]) and dialysis-related amyloidosis (DRA, [29]), respectively. Fibrillogenesis of lysozyme was induced using two alternative methods, which made it possible to obtain protein aggregates with a polymorphic structure [30]. Thus, experiments were carried out using the amyloid fibrils with different types of morphology, as well as with different primary and secondary structures of amyloid-forming proteins, which allowed us to draw a conclusion about the universality of the observed degradation effect of trypsin.

\section{Results}

2.1. Mechanism of Amyloid Fibril Degradation Induced by Trypsin: Fragmentation, Disordering, and Monomerization

Model lysozyme amyloid fibrils, the accumulation of which leads to the development of hereditary lysozyme systemic amyloidosis (ALys amyloidosis, [28]), were selected as one of the objects of study. Literature data indicate that trypsin exhibits proteolytic activity in a narrow range of neutral $\mathrm{pH}$ [31-33]. In this regard, lysozyme amyloid fibrils prepared using the standard protocol (see Materials and Methods) were transferred to a solution with $\mathrm{pH} 7.4$ to analyze the action of trypsin. Previously, we showed that mature lysozyme fibrils, transferred to physiological conditions, were stable for at least a week [34]. Based on the literature, the ratio of trypsin and amyloid-forming protein in the experiment was chosen equal to 1: 125 [35-37].

Considering the fact that trypsin is susceptible to autolysis, first of all, we checked the rate of this process in phosphate buffer with $\mathrm{pH} 7.4$ at $37^{\circ} \mathrm{C}$ using fluorescence spectroscopy and SDS-PAGE (Figure S1). This allowed us to determine the duration of the experiment on fibril degradation. It turned out that, under the chosen conditions, trypsin actually underwent autolysis, and after $24 \mathrm{~h}$, the band corresponding to this protein on SDS-PAGE became indistinguishable (Figure S1A). Similar results, indicating the autolysis of trypsin during the day, were obtained when analyzing changes in the intrinsic tryptophan fluorescence intensity and parameter $A$ of the protease (parameter $A$ is the ratio of fluorescence intensities at wavelengths of 320 and $365 \mathrm{~nm}$, sensitive to the position and shape of the fluorescence spectrum) [38,39]. Thus, it was concluded that, under the chosen conditions, trypsin could be active for at least $24 \mathrm{~h}$. For example, residual activity of trypsin was observed in a concentrated solution of BSA even after prolonged 
incubation (Figure S2). Since the weight ratio of trypsin to amyloidogenic protein in the sample was 1 to 125, it is highly likely that trypsin predominantly affects the amyloidforming protein, and not itself. It is important to note that trypsin was not previously incubated in neutral buffer separately but was added directly into the fibril suspension. In this regard, it was decided to study the effect of trypsin on fibrils for at least $24 \mathrm{~h}$ and while detectable changes are observed.

Next, we studied trypsin binding to fibrils. For this aim, amyloid fibrils after trypsin adding and the enzyme alone (control) were incubated in PBS (pH 7.4) for $10 \mathrm{~min}$ at $37^{\circ} \mathrm{C}$. Then, trypsin was inactivated using phenylmethylsulfonyl fluoride (PMSF), and the samples were centrifuged at high speed $(18,000 \mathrm{rpm})$ for $1 \mathrm{~h}$. Supernatants of both samples were collected and analyzed using SDS-PAGE under denaturing conditions (Figure S3). The results indicated the absence of trypsin in the supernatant of the sample with amyloid fibrils, although in the supernatant of the control (without fibrils), a bright band corresponding to the protease molecular weight was clearly seen (Figure S3). This means that in the sample with amyloids, all trypsin molecules remained in the pellet in a bound to fibrils state. Thus, the trypsin binding to amyloid fibrils was experimentally confirmed.

In order to study trypsin's effect on amyloid stability, we detected changes in the intrinsic photophysical characteristics of fibrils and the characteristics of specific fluorescent probes bound to them (Figure 1). It was noted that the most significant change in the recorded characteristics occurred in the first few hours after the start of the experiment, and then smoother changes were observed over the next five days. Further, we investigated changes in the structure and properties of amyloid fibrils after them being exposed to trypsin, but we do not claim that trypsin hydrolyzes the fibrils during all five days of the experiment. These changes can both directly be caused by the enzyme present in the fibril sample (during the first day) and can be a delayed effect of short-term exposure to trypsin after its autolysis (for example, as a result of fibrils' destabilization, which promotes their further gradual degradation).

Visualization of structural changes in amyloid fibrils by TEM at $20 \mathrm{~min}, 4 \mathrm{~h}$, and 5 days after the trypsin addition was performed (Figure 1A). We observed that after the addition of the protease to amyloids suspension, defragmentation of fibrils took place; however, the formed fragments of fibrils remained ordered (for $20 \mathrm{~min}$ ); after that, the structure of these fragments was "fluffed" (with an increase in the incubation time to $4 \mathrm{~h}$ ). Our results indicate that the samples of fibrils five days after the addition of trypsin contain non-fibrillar aggregates of various sizes (from several tens of monomeric subunits to the size of a mature amyloid fibril). These aggregates can be a result of fibril degradation induced by trypsin, as well as association of the products of proteolytic degradation of fibrils with each other. It should be noted that along with the products of proteolytic degradation full-length mature amyloid fibrils were retained in the sample.

We also checked whether degradation of amyloids induced by some external proteolytic activity (not coming from the trypsin) occurs in the control sample with no trypsin added. Tested samples were incubated at $37^{\circ} \mathrm{C}$ in phosphate buffer. Intact amyloids were stable during at least a one-week period, as confirmed by TEM (Figure S4). 


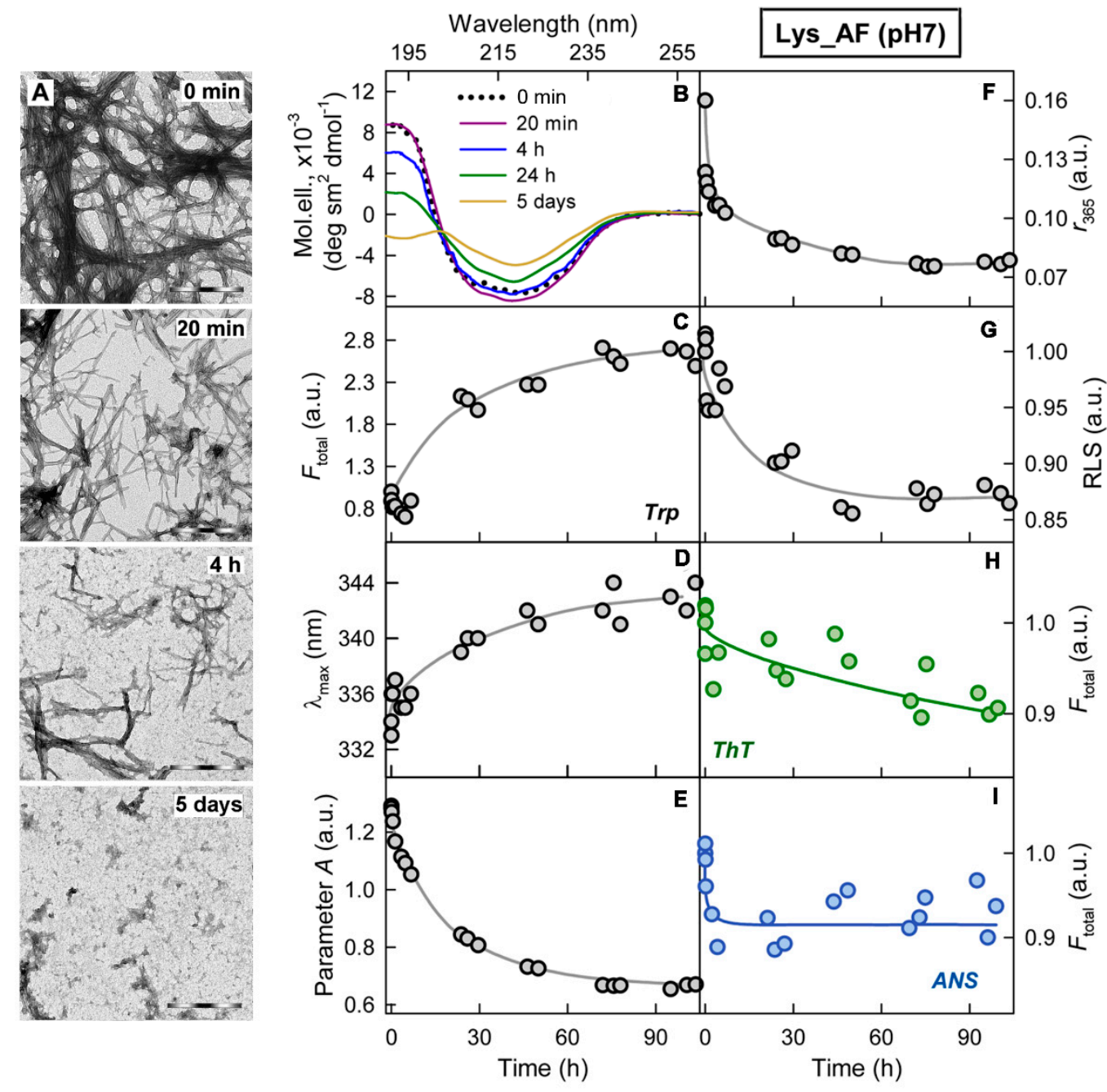

Figure 1. Trypsin-induced degradation of amyloid fibrils formed from lysozyme at pH 7. (A) The electron micrographs of amyloid fibrils in the absence and at different time points after the addition of trypsin to the samples. Scale bars are equal to $1 \mu \mathrm{m}$. (B) Changes in far UV CD spectra of amyloid samples. (C) Changes in total fluorescence intensity of amyloid fibrils at the excitation wavelength of $295 \mathrm{~nm}$. (D) Changes in wavelength of the fluorescence spectrum maximum of amyloid fibrils $\left(\lambda_{\max }\right)$. (E) Changes in parameter A of amyloid fibrils, $\lambda_{\mathrm{ex}}=295 \mathrm{~nm}$. (F) Changes in fluorescence anisotropy of amyloid fibrils, $\lambda_{\mathrm{ex}}=295 \mathrm{~nm}$, and $\lambda_{\mathrm{em}}=365 \mathrm{~nm}$. (G) Changes in Rayleigh Light Scattering of amyloid fibrils. (H) Changes in the total fluorescence intensity of ThT and (I) ANS in the presence of amyloid fibrils. The values at the panels $(\mathbf{C}, \mathbf{H}, \mathbf{I})$ are normalized to the values for fibrils in the absence of the protease. The experiments were performed under physiological conditions (in $20 \mathrm{mM}$ sodium phosphate buffer solution, $\mathrm{pH}$ 7.4) and weight ratio of fibrils to trypsin was kept at 125:1. The standard error of the mean is determined for a confidence interval of 0.95 and does not exceed $10 \%$.

To assess the degree of protein aggregates degradation, samples before and five days after the addition of protease were centrifuged at high speeds ( $2 \mathrm{~h}, 18,000 \mathrm{rpm})$, after which the supernatant was collected and analyzed. Analysis of the supernatant sample untreated with protease showed the absence of fibril fragments and disordered aggregates as confirmed by TEM (Figure 2A, TEM data), as well as by the closeness to 0 of its optical density. This indicates the stability of the studied aggregates and the absence of processes of their spontaneous degradation. According to TEM data (Figure 2A), degraded fibrils fragments, unstructured protein aggregates, were present in the supernatant of the sample after trypsin exposure. Using absorption spectroscopy, it was shown that the proportion of the degraded fraction in supernatant is about $20 \%$ of the initial concentration of amyloid fibrils (Figure 2B). It should be noted that degraded aggregates partially precipitated during centrifugation and large non-fibrillar associates comparable in size to amyloid fibrils were 
found in the pellet. Thus, the real fraction of fibril degradation products substantially exceeds $20 \%$. We also show that increase in trypsin concentration led to an increase in the proportion of the degraded fraction in the sample (Figure S5).
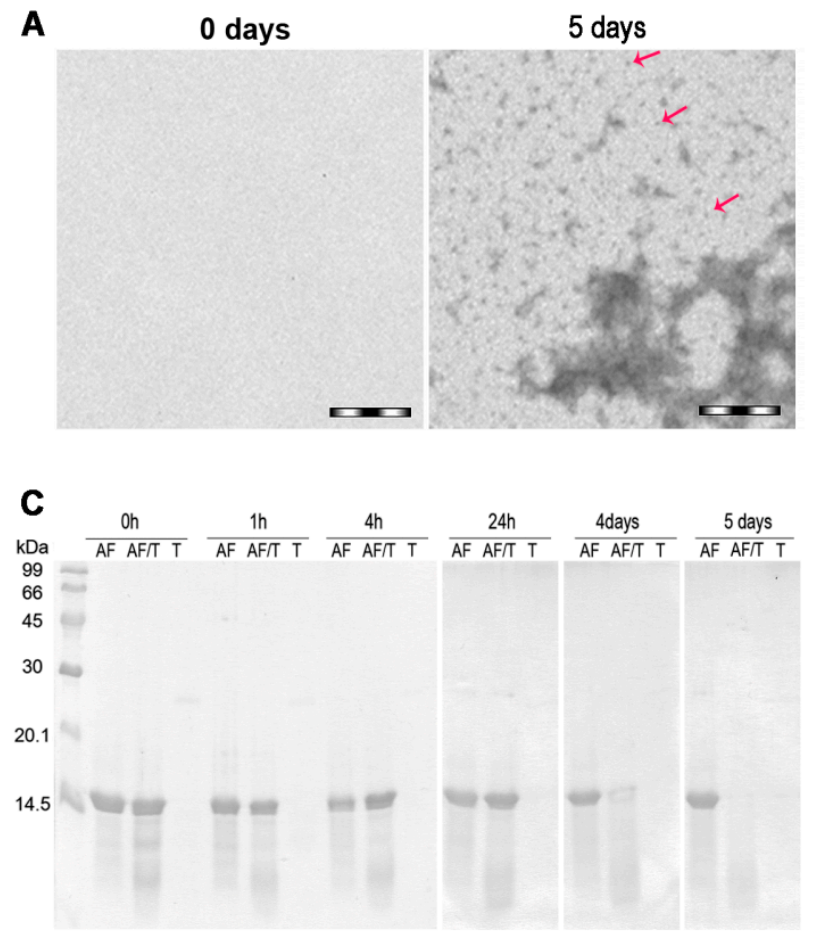

5 days

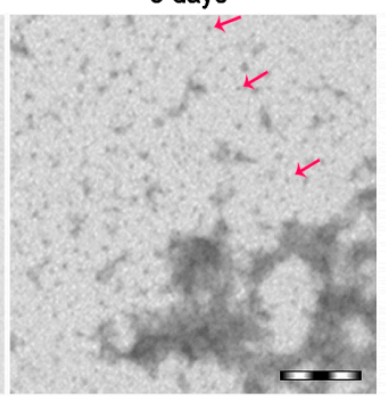

days
B $\square$ Pellet+Supernatant

a Pellet $\quad$ Supernatant

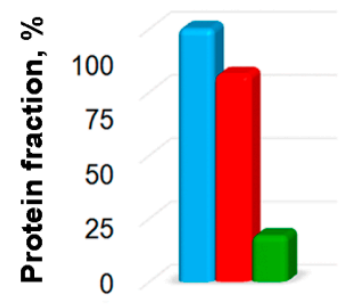

D

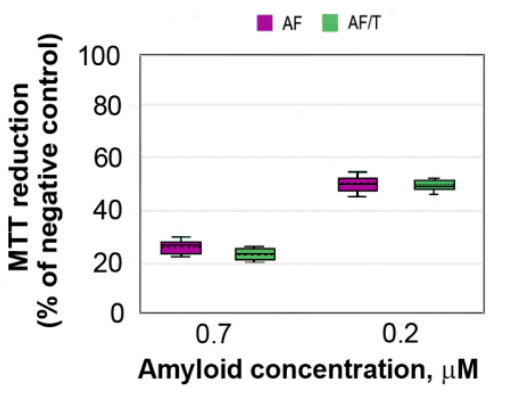

Figure 2. Stability and inhibitory effect on cells of exposed to trypsin amyloid fibrils formed from lysozyme at pH 7. (A) The electron micrographs of supernatant collected by centrifugation of amyloid fibrils before and five days after the addition of trypsin. Scale bars are equal to $200 \mathrm{~nm}$. The estimated size of aggregates corresponds to 20 (shown by red arrows) or more monomeric protein molecules as evaluated by ImageJ. (B) Redistribution of the protein between supernatant and pellet obtained by centrifugation of amyloid fibrils treated with trypsin. (C) Trypsin-induced degradation of lysozyme amyloid fibrils detected by SDS-PAGE under denaturing conditions. The amyloid fibrils alone (AF), in the presence of trypsin (AF/T) and trypsin (T) solutions, were incubated in PBS at $37^{\circ} \mathrm{C}$, and aliquots were taken at different times. Molecular weight of lysozyme and trypsin is 14.3 and $23.3 \mathrm{kDa}$, respectively. (D) Dose-dependent inhibition effect of amyloid fibrils on HeLa cells determined by MTT assay. Cells were exposed to amyloid fibrils, intact (AF) or five days after the addition of trypsin to the sample (weight ratio of fibrils to trypsin was kept at 7.5/1) (AF/T), at indicated concentrations for $24 \mathrm{~h}$. Data are expressed as medians and interquartile ranges, whiskers denote $1.5 \times \mathrm{IQR}$. Experiments were repeated at least three times with similar results.

The effect of trypsin on lysozyme amyloid fibrils was also analyzed by SDS-PAGE under denaturing conditions (Figure 2C). Samples of trypsin in PBS at the same concentration as in samples with fibrils, as well as amyloid fibrils in the absence of trypsin, were used as controls. Surprisingly, we did not observe a band corresponding to the molecular weight of the protease in the analyzed sample immediately after the mixing fibrils with trypsin, in contrast to the control sample (freshly prepared trypsin only) (Figure 2C, $0 \mathrm{~h}$ ). Similar results were obtained earlier in the study of the interaction of Abeta-peptide amyloids with trypsin [19]. This indicates that the affinity of trypsin binding to fibrils is so high that this interaction does not destroy either the effect of ionic detergent (SDS) or boiling the sample (for $5 \mathrm{~min}$ ). It should be noted that the band corresponding to trypsin did not appear in the samples with fibrils for five days. At the same time, after the addition of trypsin to the fibril suspension, the content of monomeric lysozyme first increased and then decreased (according to the analysis of the monomeric fraction ratio in the samples before and after trypsin exposure, shown in Figure S6), which confirmed the effect of protease on amyloids. We did not observe a band corresponding to the molecular weight of monomeric lysozyme 
five days after the addition of trypsin, which indicated an almost complete proteolytic degradation of lysozyme monomers released under the action of trypsin. In addition, a decrease in the number of protein fragments that are formed immediately after the addition of trypsin can be noted, pointing at their degradation.

Interestingly, according to the literature, compact globular lysozyme in its native state is not hydrolyzed by a number of proteolytic enzymes, including trypsin, chymotrypsin, and papain, which indicates the localization of protease cleavage binding sites within the protein globule [40]. However, these enzymes can hydrolyze denatured lysozyme [41]. We were convinced of the stability of monomeric native lysozyme exposed to trypsin using SDS-PAGE under denaturing conditions: the intensity of the band corresponding to monomeric lysozyme did not change five days after the addition of trypsin to protein (Figure S7). The fact that during this time there is a significant degradation of amyloid fibrils formed from this protein allows us to conclude that amyloid cleavage sites are more exposed than in monomeric protein.

In order to reveal the structural changes of the studied lysozyme amyloid fibrils induced by trypsin, we analyzed the results obtained using various spectroscopic methods, such as intrinsic UV fluorescence of proteins and CD spectroscopy of fibrils in the far UV region, and also an approach based on the analysis of the interaction of amyloid fibrils with fluorescent probes. The amyloid-specific dye thioflavin T (ThT) [42-44] and the hydrophobic probe 1-anilinonaphthalene-8-sulfonic acid (ANS) [45-47] were used, which are widely known probes to detect the formation of amyloid fibrils and study their structure and stability [48-51].

After the treatment of amyloid fibrils with trypsin, a significant decrease in the values of their photophysical characteristics such as parameter $A[38,39]$ (Figure 1E) and fluorescence anisotropy (Figure 1F) as well as a shift in the maximum of the spectrum of intrinsic UV fluorescence of the sample to longer wavelengths was observed (Figure 1D). In addition, after trypsin exposure, an increase in the integral fluorescence intensity of tryptophan residues of amyloid fibrils was found (Figure 1C). Such changes in photophysical characteristics are usually observed during protein denaturation [49,52]. As already noted, five days after the addition of trypsin to fibrils, significant changes in the values of the recorded parameters were no longer observed (Figure 1). However, the values of these parameters did not reach the values characteristic of lysozyme in the unfolded state, in which all tryptophan amino acid residues of the protein are exposed to water, which determines the low value of the parameter $A(A=0.45)$ and fluorescence anisotropy $\left(r_{365}=0.05\right)$, as well as the long wavelength position of the fluorescence spectrum maximum $\left(\lambda_{\max }=350 \mathrm{~nm}\right)$ of the sample [53-57]. The observed difference in the values of the photophysical characteristics of the studied fibrils, measured five days after the addition of trypsin, from the values characteristic of the protein in the unfolded state, may be due to the following facts: (1) the sample still contains a significant amount of mature intact amyloid fibrils that have not been exposed to protease and also (2) the monomers of the amyloid-forming protein in the aggregates are not completely denatured after trypsin exposure. To understand the reasons for the observed differences, we compared the samples of amyloid fibrils five days after the addition of trypsin at trypsin/protein ratios of 1:125 and 1:1. It turned out that the characteristics of the sample treated with higher concentration of trypsin were even closer to the characteristics of the denatured protein. Following that, we sedimented amyloid fibrils and large aggregates by centrifugation and evaluated the photophysical characteristics of the protein that remained in the supernatant. As we expected, these characteristics practically coincided with the characteristics of the fully denatured protein (Figure S8).

Four hours after the addition of protease to the sample with amyloids, a change in the shape of the CD spectrum of fibrils in the region of $190 \mathrm{~nm}$ was observed (Figure 1B). An even more significant change in the shape of the CD spectra (not only in the shortwavelength region, but also in the region of the minimum at $220 \mathrm{~nm}$ ) was detected $24 \mathrm{~h}$ and five days after adding trypsin to the sample with amyloids. The obtained data indicate that 
the secondary structure of lysozyme subunits in the amyloid fibril changes significantly after treatment of the samples with trypsin. In order to assess the nature of these changes, we analyzed the content of various elements of the secondary structure in the sample using special software CDPro [58]. It was shown that the addition of trypsin to the studied amyloid fibrils led to an increase in the proportion of disordered structure due to a decrease in the proportion of ordered $\alpha$-helical structure and $\beta$-strands in amyloid-forming proteins (Figure S9A). Considering the fact that $\beta$-strands form the backbone of the amyloid fibril, the observed changes confirm the assumptions about the degradation of amyloid fibrils. In this case, the addition of trypsin leads to a change in the structure of not only amyloidogenic ( $\beta$-folded) but also non-amyloidogenic protein fragments.

Trypsin treatment of the studied amyloid fibrils was also accompanied by a decrease in the fluorescence intensity of specific dyes ThT (Figure 1H) and ANS (Figure 1I) bound to fibrils. According to the literature, ThT incorporates into the grooves formed by the side chains of amino acids of the amyloid fibril backbone along the fiber axis perpendicular to the beta-sheets [59], and ANS is a hydrophobic probe interacting with protein associates [45,46]. Thus, the dyes are likely to bind to different sites of amyloids, which is in line with the results of the work [48]. We believe that it explains the difference of kinetic dependences of fibril degradation monitored by ANS and ThT fluorescence. Different ANS and ThT binding kinetics was observed in the process of fibrillogenesis previously [60]. It can be assumed that the change in ThT fluorescence indicates degradation of amyloid fibers, and ANS fluorescence mainly reflects the fibril declasterization and degradation of non-fibrillar protein aggregates. This is in good agreement with TEM data indicating fragmentation and decreased ordering of amyloids in the presence of trypsin (Figure 1A). The significant reduction in Rayleigh light scattering (RLS) of amyloid fibril samples after the addition of trypsin confirms the disintegration of fibrillar clots and destruction of the fibrillar core (Figure 1G).

To assess the effect of trypsin on the cytotoxicity of amyloid fibrils, the metabolic activity of Hela cells was determined using the MTT test in the presence of amyloids before and five days after the addition of protease. First of all, trypsin at the used concentration was shown to be non-toxic to cells (Figure S10). It turned out that the level of reduced MTT was the same for samples of amyloid fibrils exposed to trypsin and for intact amyloids (data not shown). This indicates that the action of trypsin on fibrils did not change their toxicity to cells. A significant increase in the proportion of degraded fraction of amyloid fibrils in the sample with a 17-fold increase in trypsin concentration also did not lead to a change in toxicity (Figure 2D), despite a significant decrease of intact amyloids in the sample. In order to explain these results, the metabolic activity of Hela cells was determined in the presence of monomeric lysozyme and its fragments obtained as a result of proteolytic degradation of the protein (Figure S10) (to obtain protein fragments, protein was preliminary denatured). It turned out that monomeric lysozyme and its fragments did not affect cell viability at a concentration equal to the concentration of fibrils in the experiment. It means that if only these protein fractions were the products of degradation, the total cytotoxicity of the sample after trypsin exposure should have decreased. It can be assumed that, along with lysozyme fragments and monomers, proteolytic degradation of fibrils also results in the formation of non-fibrillar aggregates that are toxic to cells (probably even more cytotoxic than amyloid fibrils themselves). At the same time, the quantitative ratio of cytotoxic and non-cytotoxic protein fractions is such that the cytotoxic effect of non-fibrillar aggregates is leveled and, as a result, the viability of cells before and after their treatment with trypsin remains unchanged.

We tried to estimate the size of aggregates formed after trypsin exposure. We analyzed the aggregates, formed after treatment of amyloid fibrils with trypsin (trypsin/protein ratio of 1:7.5), using pseudo-native SDS-PAGE in $8 \%$ polyacrylamide gel [61]. Obtained results indicate the absence in the sample of fractions with molecular weights less than $220 \mathrm{kDa}$ (Figure S11). Increase in the concentration of trypsin in the sample (trypsin/protein ratio of 1:1) led to similar results. Our rough estimate of the size of aggregates visualized by 
TEM (Figure 2A and Figure S12) allowed us to conclude that they consist of 20 or more monomeric protein subunits (which may explain their absence on SDS-PAGE) and have a broad size range. The linear dimensions of some aggregates are comparable to the size of intact amyloid fibrils (Figure S12). A higher cytotoxicity of such large aggregates, representing degraded amyloids, relative intact fibrils have been already demonstrated by us previously for the same fibrils treated with a protein with a chaperone activity of alpha-B-crystallin [34].

Based on the obtained results, it is concluded that trypsin-induced degradation of the studied lysozyme amyloid fibrils occurs according to the following mechanism: (1) first, amyloid clots are declustering, and amyloid fibers are fragmented; (2) then, the structure of shortened fibril fragments "decompacts" and becomes less ordered, (3) after which these aggregates degrade to monomers, which, in turn, degrade into short fragments. In this case, despite the fact that proteolytic cleavage of fibrils to short non-toxic protein fragments occurs, the total cytotoxicity of the sample after trypsin exposure does not decrease, which may indicate the presence of highly toxic non-fibrillar aggregates in the sample.

\subsection{Relationship of Amyloid Fibrils Degradation Induced by Trypsin and Their Polymorphism}

Analysis of the lysozyme amino acid sequence indicates that the protein has 17 trypsin cleavage sites located in different parts of the protein (Scheme 1).

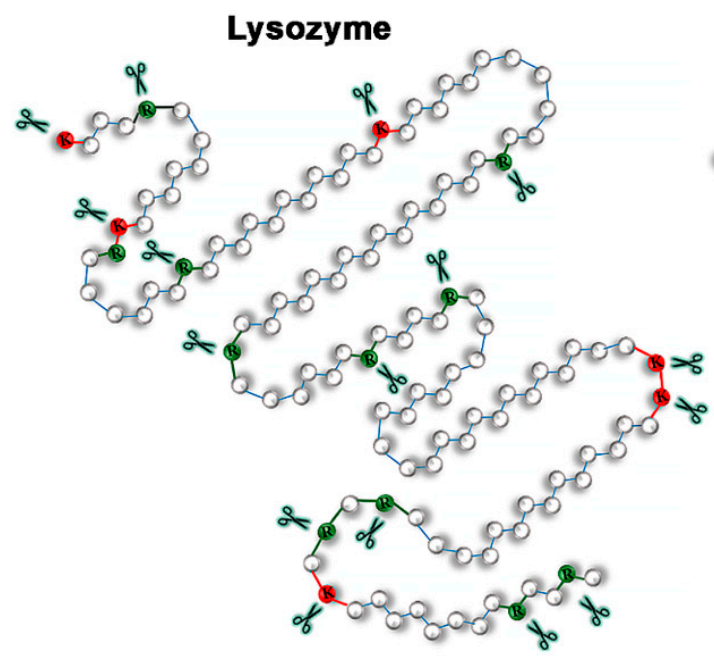

\section{Beta-2-microglobulin}

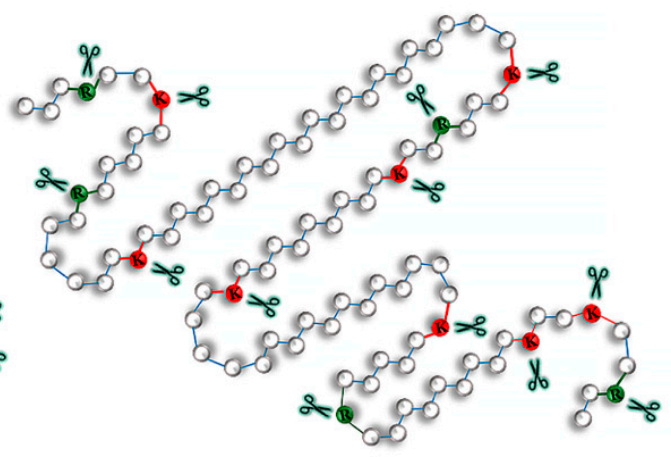

Scheme 1. Trypsin cleavage sites in the lysozyme and beta-2-microglobulin amino acid sequences. Lysine (K) and Arginine (R) amino acid residues in the primary sequence of the proteins are highlighted in red and green color, respectively.

Taking into account that the conformation of lysozyme significantly affects its stability, we can suggest that the mechanism of protease action on fibrils may depend on the secondary and tertiary structures of amyloid-forming protein, that is, on different localization of proteolytic cleavage sites. In order to understand this issue, we investigated the effect of protease on lysozyme amyloids formed under alternative conditions (at acidic $\mathrm{pH}$ ) [30,34].

Lysozyme amyloid fibrils prepared under acidic conditions ( $\mathrm{pH}$ 2.0), as well as fibrils previously prepared under neutral conditions in the presence of $\mathrm{GdnHCl}$, were transferred to a buffer with $\mathrm{pH} 7.4$ and incubated at $37^{\circ} \mathrm{C}$. Previously, it was shown that under these conditions, fibrils retained their structure and stability for a long time [34] that corresponds to our results (Figure S4), which made it possible to observe the change in their characteristics induced by trypsin within a week (Figure 3A-I). The morphology of the prepared amyloid fibrils was analyzed by TEM (Figure 3A). It turned out that lysozyme fibrils, obtained under acidic conditions, were thin long fibers, visually similar to fibrils formed from the same protein at neutral $\mathrm{pH}$ of the solution in the presence of denaturant (Figures 1A and 3A). However, TEM data suggested that amyloids prepared under different conditions have different tendencies to clustering. In order to prove this assumption, we 
analyzed fibril samples using confocal microscopy in the presence of a ThT fluorescent probe. Analysis of confocal microscopy results (Figure 4A), as well as the RLS values of the studied aggregates (Figures 1G and 3G), confirmed our assumption about the smaller size of fibrillar clots in the sample obtained in the acid buffer in comparison to the aggregates formed in the alternative conditions.

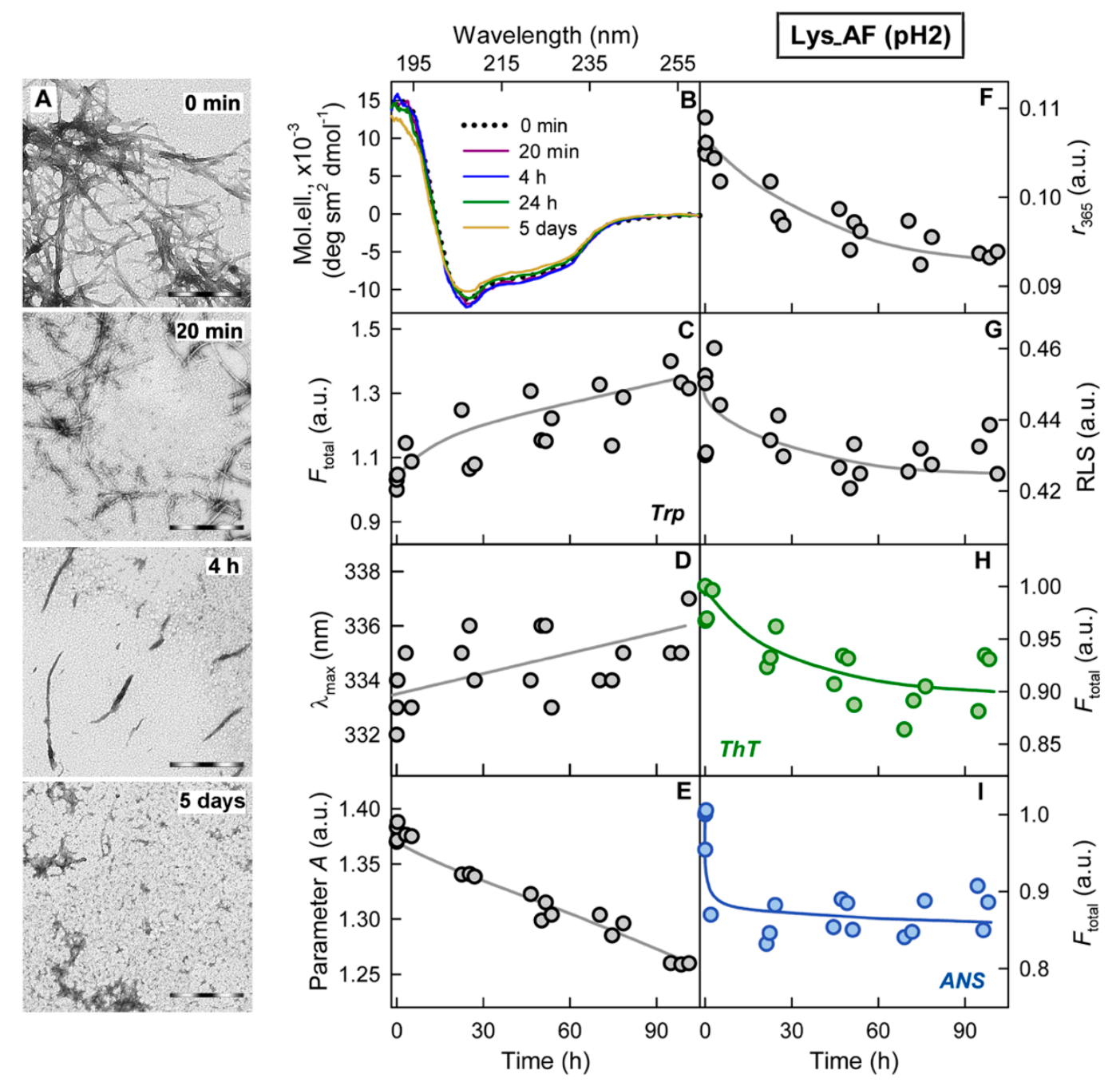

Figure 3. Trypsin-induced degradation of amyloid fibrils formed from lysozyme at pH 2. (A) The electron micrographs of amyloid fibrils in the absence and at different time points after the addition of trypsin to the samples. Scale bars are equal to $1 \mu \mathrm{m}$. (B) Changes in far UV CD spectra of amyloid samples. (C) Changes in total fluorescence intensity of amyloid fibrils at the excitation wavelength of $295 \mathrm{~nm}$. (D) Changes in wavelength of the fluorescence spectrum maximum of amyloid fibrils $\left(\lambda_{\max }\right)$. (E) Changes in parameter $A$ of amyloid fibrils, $\lambda_{\mathrm{ex}}=295 \mathrm{~nm}$. (F) Changes in fluorescence anisotropy of amyloid fibrils, $\lambda_{\mathrm{ex}}=295 \mathrm{~nm}, \lambda_{\mathrm{em}}=365 \mathrm{~nm}$. (G) Changes in Rayleigh Light Scattering of amyloid fibrils. (H) Changes in the total fluorescence intensity of ThT and (I) ANS in the presence of amyloid fibrils. The values at the panels $(\mathbf{C}, \mathbf{H}, \mathbf{I})$ are normalized to the values for fibrils in the absence of the protease. The experiments were conducted under physiological conditions ( $\mathrm{pH}$ 7.4), and weight ratio of fibrils to trypsin was kept at 125:1. The measurements were performed in $20 \mathrm{mM}$ sodium phosphate buffer solution ( $\mathrm{pH} 7.4$ ). The standard error of the mean is determined for a confidence interval of 0.95 and does not exceed $10 \%$. 
A
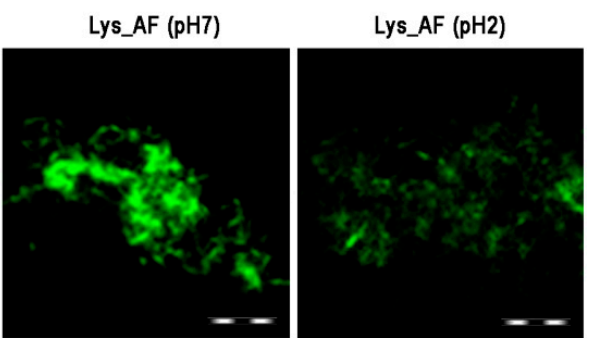

C
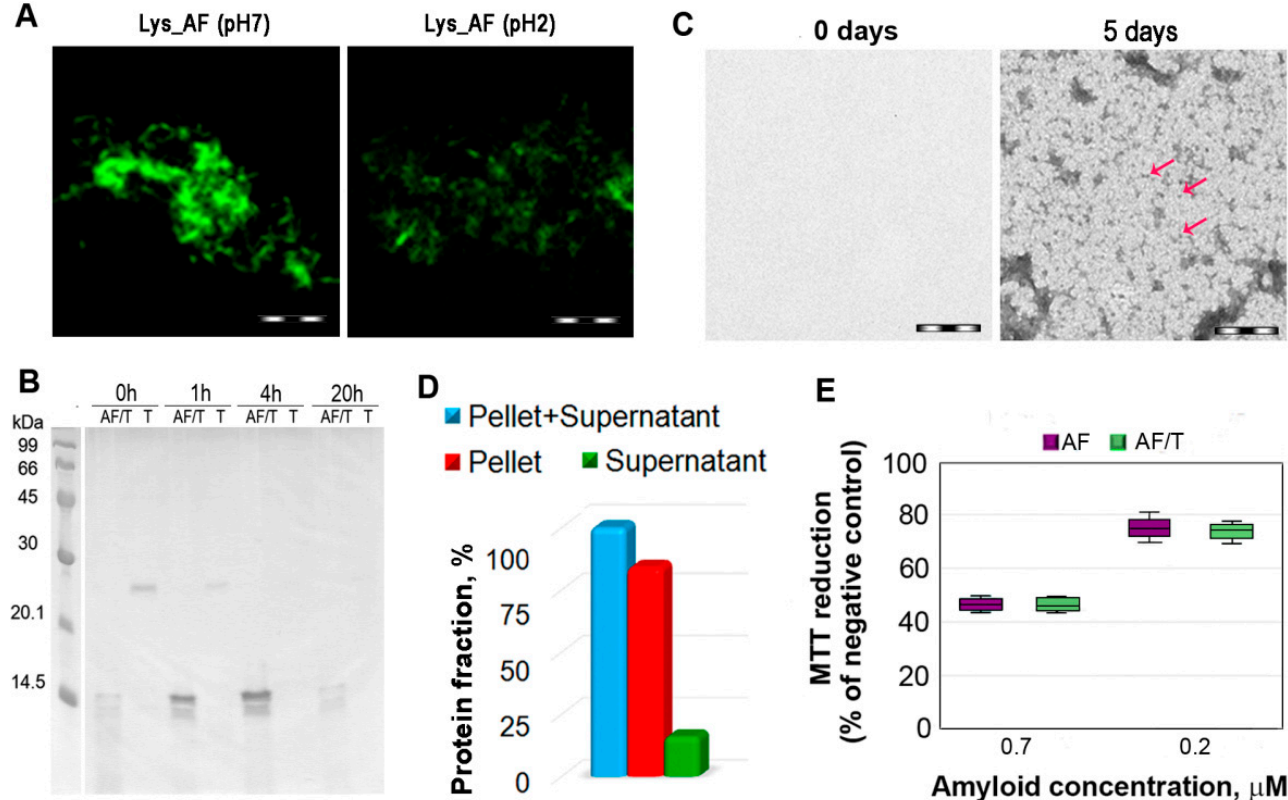

D
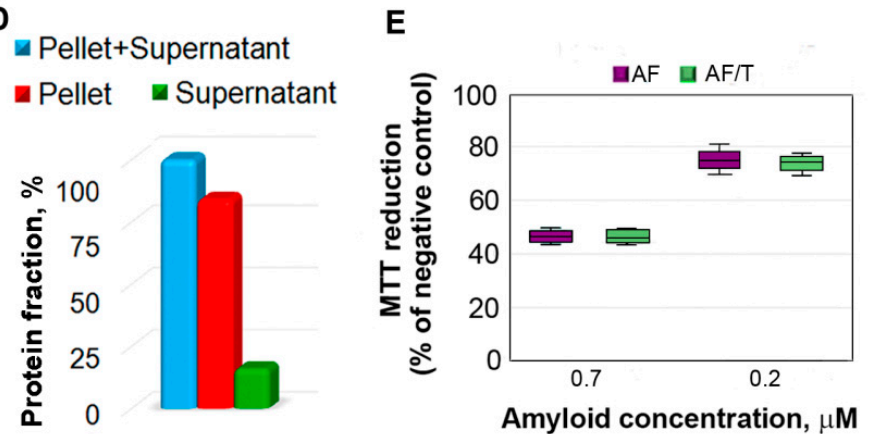

Figure 4. Stability and inhibitory effect on cells of exposed to trypsin amyloid fibrils formed from lysozyme at pH 2. (A) The difference in morphology of amyloid fibrils formed from lysozyme at acidic $(\mathrm{pH} 2)$ and neutral ( $\mathrm{pH}$ 7) conditions visualized by confocal microscopy. Scale bars are $3 \mu \mathrm{m}$. (B) Trypsin-induced degradation of lysozyme amyloid fibrils detected by SDS-PAGE under denaturing conditions. The amyloid fibrils after the addition of trypsin (AF/T) and trypsin (T) were incubated in PBS at $37^{\circ} \mathrm{C}$, and aliquots were taken at different time points. The molecular weight of lysozyme and trypsin is 14.3 and $23.3 \mathrm{kDa}$, respectively. (C) The electron micrographs of supernatant collected by centrifugation of amyloid fibrils before and five days after the addition of trypsin to the sample. Scale bars are equal to $200 \mathrm{~nm}$. The estimated size of aggregates corresponds to 20 (shown by red arrows) or more monomeric protein molecules as evaluated by ImageJ. (D) Redistribution of the protein between supernatant and pellet obtained by centrifugation of amyloid fibrils treated with trypsin. (E) Dose-dependent inhibition effect of amyloid fibrils on HeLa cells determined by MTT assay. Cells were exposed to amyloid fibrils, intact (AF) or five days after the addition of trypsin (weight ratio of fibrils to trypsin was kept at 7.5/1) $(\mathrm{AF} / \mathrm{T})$, at indicated concentrations for $24 \mathrm{~h}$. Data are expressed as medians and interquartile ranges, and whiskers denote $1.5 \times$ IQR. Experiments were repeated at least three times with similar results.

It is noteworthy that the values of the parameter $A$ and fluorescence anisotropy of lysozyme fibrils prepared at acidic $\mathrm{pH}$ (Figure $3 \mathrm{E}, \mathrm{F}$ ) are lower than the values of the corresponding characteristics for lysozyme fibrils obtained at neutral $\mathrm{pH}$ (Figure 1E,F). At the same time, the proportion of $\beta$-folded structure in lysozyme monomers, which form fibrils prepared at acidic $\mathrm{pH}$, is significantly lower than in fibrils obtained at neutral $\mathrm{pH}$, while the proportion of $\alpha$-helical elements, on the contrary, is higher (Figure S9A,B). These data indicate that the structure of lysozyme molecules in amyloid fibrils prepared under different conditions is not identical.

The observed polymorphism of lysozyme amyloid fibrils affects their cytotoxicity, which is in good agreement with our earlier data [34,49]. Cell viability in in vitro experiments when cells were treated with lysozyme fibrils prepared at acidic $\mathrm{pH}$ turned out to be higher than in the presence of lysozyme fibrils obtained at neutral $\mathrm{pH}$, as evidenced by the difference in the level of reduced MTT in the presence of different types of fibrils by about $20 \%$ (Figures 2D and 4E).

The results of our experiments showed that, when trypsin was added to the suspension of fibrils obtained at acidic $\mathrm{pH}$, after $10 \mathrm{~min}$, the enzyme in a soluble form was not detected in the buffer (as in the case of lysozyme fibrils obtained at neutral pH) (Figure S3). This means that all trypsin molecules in the sample are in a fibril-bound state. Thus, the change in the structure of lysozyme fibrils did not break their ability to interact with trypsin.

Next, we examined whether the mechanism of action of trypsin changes with the change of fibrils structure. The experiment was carried out for five days, as in the case of 
fibrils obtained under alternative conditions. According to TEM data, fragmentation of lysozyme amyloid fibrils formed under acidic conditions begins as early as $20 \mathrm{~min}$ after the addition of the protease (that is, earlier than for amyloid fibrils prepared at neutral $\mathrm{pH}$ (Figure 3A). These results are consistent with the data obtained by SDS-PAGE under denaturing conditions (Figure 4B). It turned out that already $20 \mathrm{~h}$ after the addition of trypsin to fibrils obtained at acidic $\mathrm{pH}$, a significant decrease in the intensity of the band corresponding to monomeric lysozyme was observed. At the same time, the intensity of this band did not change even after $24 \mathrm{~h}$ after adding trypsin to fibrils prepared at neutral $\mathrm{pH}$.

It can be assumed that the lower rate of degradation of lysozyme fibrils obtained at physiological $\mathrm{pH}$ is due to a higher degree of clustering, i.e., to a lower availability of proteolytic cleavage sites. Fragmentation of these fibrils with trypsin probably requires preliminary disaggregation of fibrillar clots. However, despite the different rates of degradation, the mechanism of action of trypsin on different types of lysozyme fibrils turned out to be identical: with the time, the fragments of fibrils were "decompacted" and lost their rigid structure. This mechanism of trypsin action was also confirmed by a decrease in the fluorescence intensity of ANS (Figure 3I) and ThT (Figure 3H) in the sample with amyloid fibrils.

It is important to note that the value of the fluorescence intensity of bound dyes (Figure 3H,I), as well as the scale of their RLS (Figure 3G) recorded five days after the addition of trypsin to lysozyme amyloid fibrils prepared under acidic conditions, is comparable in magnitude with the degree of changes in these characteristics obtained for lysozyme amyloid fibrils prepared under neutral conditions. (Figure 1G-I). The proportion of the degraded fibril fraction five days after the addition of trypsin to different types of lysozyme amyloids (Figures 2A and 4C) determined using the samples after centrifugation is also similar (Figures 2B and 4D). It was shown that an increasing of trypsin concentration can lead to differences in proportion of this fraction in the case of different amyloids (Figure S5). At the same time, the analysis of aggregates, formed after the treatment of different types of lysozyme amyloid fibrils with trypsin in different concentrations using pseudo-native SDSPAGE in $8 \%$ polyacrylamide gel [61], showed similar results. Obtained results indicate the absence in the samples of fractions with molecular weights less than $220 \mathrm{kDa}$ (Figure S11).

The results of the assessment of cell viability in the presence of amyloid fibrils indicate that the cytotoxicity of both types of amyloids after their treatment with trypsin (including, in the case of an increase in its concentration by 17 times) practically does not change compared to intact fibrils (Figure 4E), which indicates similar protein species formed as a result of proteolytic cleavage of the studied amyloids, which does not contradict the TEM data (Figure S12).

It is interesting that despite a similar mechanism of lysozyme amyloid fibrils degradation under the action of trypsin, the recorded change in the intrinsic characteristics of tryptophan fluorescence of amyloid fibrils obtained at acidic $\mathrm{pH}$ turned out to be less pronounced (Figure $3 \mathrm{C}-\mathrm{F}$ ) than in the case of lysozyme fibrils prepared at neutral $\mathrm{pH}$ (Figure 1C-F). In addition, only a slight decrease in the CD signal was observed without a significant change in the shape of the spectrum for amyloid fibrils prepared at acidic $\mathrm{pH}$ after the trypsin effect (Figure 3B). However, the assessment of the content of secondary structure elements showed that trypsin's influence on lysozyme fibrils prepared at acidic $\mathrm{pH}$, as in the case of fibrils obtained at neutral $\mathrm{pH}$, still led to the transformation of the ordered secondary structure of lysozyme into a disordered one (Figure S9B). It can be assumed that the different effect of trypsin on the photophysical properties of lysozyme fibrils obtained under different conditions is due to the different structure of the protein in amyloid fibrils. The absence of a pronounced effect of proteolytic degradation of lysozyme fibrils obtained at acidic $\mathrm{pH}$ on the secondary structure of the amyloid-forming protein and the microenvironment of tryptophan amino acid residues in this protein is probably due to the structural features of lysozyme subunits in these fibrils. 
As in the case of lysozyme amyloid fibrils prepared at $\mathrm{pH}$ 7, for these amyloids, we compared the samples five days after the addition of trypsin at trypsin/protein ratios of 1:125 and 1:1. It turned out that the characteristics of the sample treated with higher concentration of trypsin were significantly closer to the characteristics of the denatured protein. Evaluation of the photophysical characteristics of the protein remained in the supernatant after sedimentation of amyloid fibrils, and large aggregates by centrifugation showed that these characteristics practically coincided with the characteristics of the fully denatured protein (Figure S8).

Based on the obtained results, it was concluded that polymorphism of amyloid fibrils originating from the same protein (differing in the degree of clustering, secondary and tertiary structures of the protein in amyloid fibrils) could affect the rate of trypsin-induced degradation of amyloid fibrils but had no impact on the mechanism of this process and the cytotoxicity of degraded amyloid aggregates. The discovered relationship between the structure of fibrils and the rate of their degradation by trypsin can become the basis for the development of a new express method for the analysis of amyloid polymorphism.

\subsection{Relationship of Amyloid Fibrils Degradation Induced by Trypsin and Primary Structure of Amyloid-Forming Protein}

In order to determine whether the amino acid sequence of the amyloidogenic protein affects the mechanism of trypsin action, we prepared amyloid fibrils on the basis of another amyloidogenic protein, beta-2-microglobulin, the accumulation of which leads to the development of dialysis-related amyloidosis (DRA, [29]). Analysis of the primary structure of beta-2-microglobulin indicates that the protein has 13 trypsin cleavage sites located in different parts of the protein (Scheme 1). SDS-PAGE results of beta-2-microglobulin sample after adding trypsin indicate that the band corresponding to the monomeric protein is noticeably weakened within $30 \mathrm{~min}$ after the addition of protease to the sample, and after $24 \mathrm{~h}$ it is no longer detected (Figure S7). Thus, it was shown that beta-2-microglobulin in native state, in contrast to lysozyme, was not resistant to the action of trypsin.

Beta-2-microglobulin amyloid fibrils were prepared under acidic conditions ( $\mathrm{pH} 2.0)$, like lysozyme fibrils, after which they were transferred to neutral conditions and incubated at $37^{\circ} \mathrm{C}$ as a control (Figure S4). As in the case of previously studied amyloid fibrils, the structure and stability of the prepared protein aggregates after the adding of trypsin were analyzed using a wide range of physicochemical approaches (Figure 5A-I). The morphology of the prepared amyloid fibrils was analyzed by TEM (Figure 5A). It turned out that beta-2-microglobulin fibrils in their morphology and degree of clustering were more similar to lysozyme amyloid fibrils obtained under acidic conditions (Figures $3 \mathrm{~A}$ and $5 \mathrm{~A}$ ) than to lysozyme fibrils obtained under neutral conditions (Figure 1A). This was also confirmed by the RLS value of beta-2-microglobulin amyloids (Figure 5G). At the same time, the content of $\beta$-strands that form the fibril core in the sample with beta-2-microglobulin fibrils turned out to be rather high (closer to the values observed for lysozyme amyloid fibrils obtained at neutral $\mathrm{pH}$ in the presence of $\mathrm{GdnHCl}$ ) (Figure S9C). Thus, the morphology of beta-2microglobulin fibrils is more similar to lysozyme fibrils obtained at acidic $\mathrm{pH}$, and their secondary structure is more similar to lysozyme fibrils prepared under neutral conditions. 

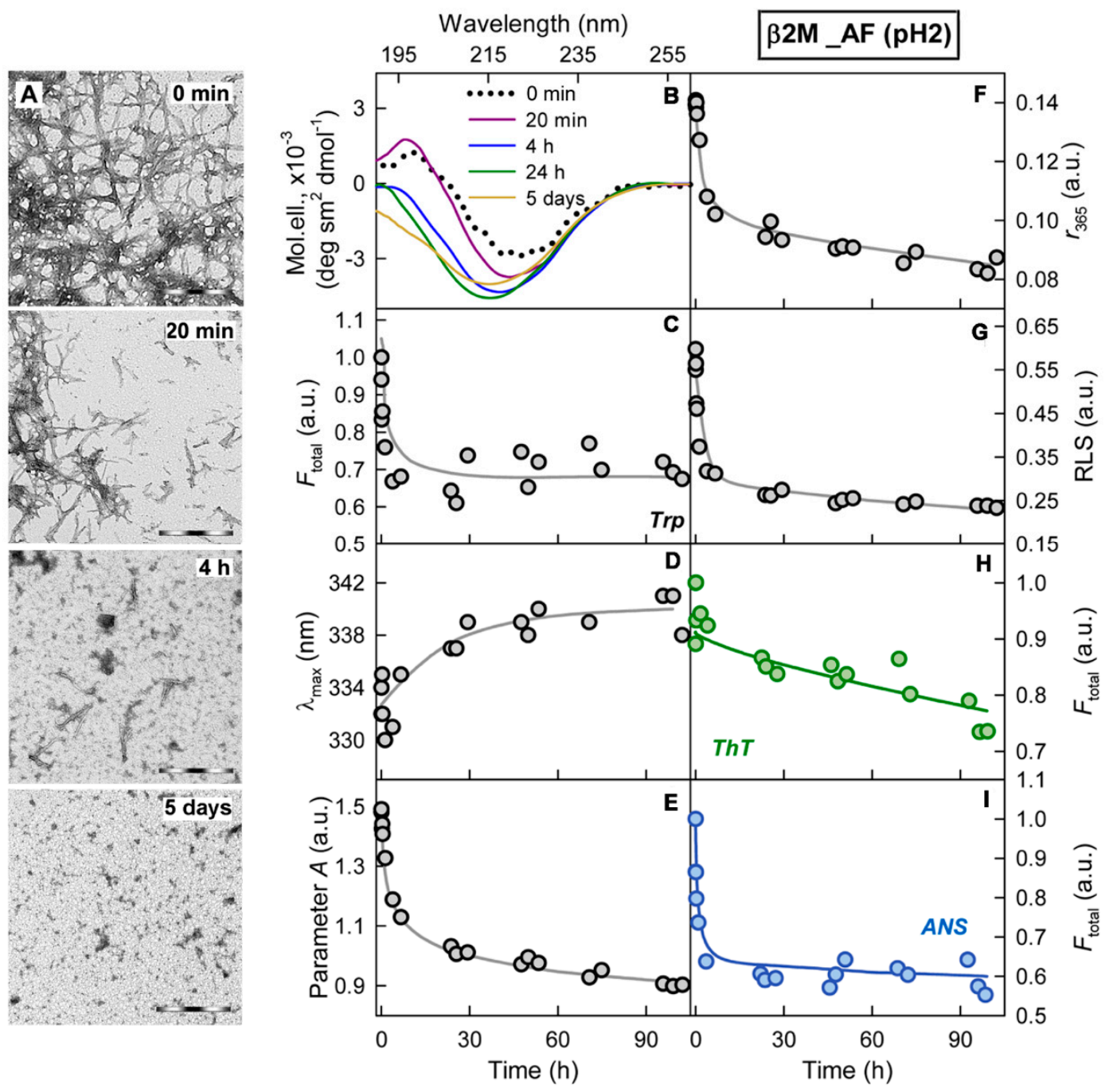

Figure 5. Trypsin-induced degradation of amyloid fibrils formed from beta-2-microglobulin ( $\beta 2 \mathrm{M})$ at $\mathrm{pH}$ 2. (A) The electron micrographs of amyloid fibrils in the absence and at different time points after the addition of trypsin to the samples. Scale bars are equal to $1 \mu \mathrm{m}$. (B) Changes in far UV CD spectra of amyloid samples. (C) Changes in total fluorescence intensity of amyloid fibrils at the excitation wavelength of $295 \mathrm{~nm}$. (D) Changes in wavelength of the fluorescence spectrum maximum of amyloid fibrils $\left(\lambda_{\max }\right)$. (E) Changes in parameter A of amyloid fibrils, $\lambda_{\mathrm{ex}}=295 \mathrm{~nm}$. (F) Changes in fluorescence anisotropy of amyloid fibrils, $\lambda_{\mathrm{ex}}=295 \mathrm{~nm}, \lambda_{\mathrm{em}}=365 \mathrm{~nm}$. (G) Changes in Rayleigh Light Scattering of amyloid fibrils. (H) Changes in the total fluorescence intensity of ThT and (I) ANS in the presence of amyloid fibrils. The values at the panels $(\mathbf{C}, \mathbf{H}, \mathbf{I})$ are normalized to the values for fibrils in the absence of the protease. The experiments were conducted under physiological conditions ( $\mathrm{pH}$ 7.4) and weight ratio of fibrils to trypsin was kept at 125:1. The measurements were performed in $20 \mathrm{mM}$ sodium phosphate buffer solution ( $\mathrm{pH}$ 7.4). The standard error of the mean is determined for a confidence interval of 0.95 and does not exceed $10 \%$.

According to TEM data, fragmentation of beta-2-microglobulin amyloid fibrils begins as early as $20 \mathrm{~min}$ after adding trypsin (as in the case of lysozyme fibrils formed at acidic $\mathrm{pH}$ (Figure 5A). These results are in good agreement with the data obtained by SDS-PAGE under denaturing conditions (Figure 6A). A significant decrease in the intensity of the band of monomeric beta-2-microglobulin was observed already $24 \mathrm{~h}$ after the addition of trypsin, as in the case of lysozyme fibrils obtained under the same conditions. In contrast, in the case of lysozyme fibrils prepared at neutral $\mathrm{pH}$, the intensity of the band of monomeric lysozyme did not change significantly $24 \mathrm{~h}$ after the addition of trypsin. The obtained results confirm the previously made the assumption that the rate of amyloid fibrils degradation is influenced by their morphology and the degree of clustering. 

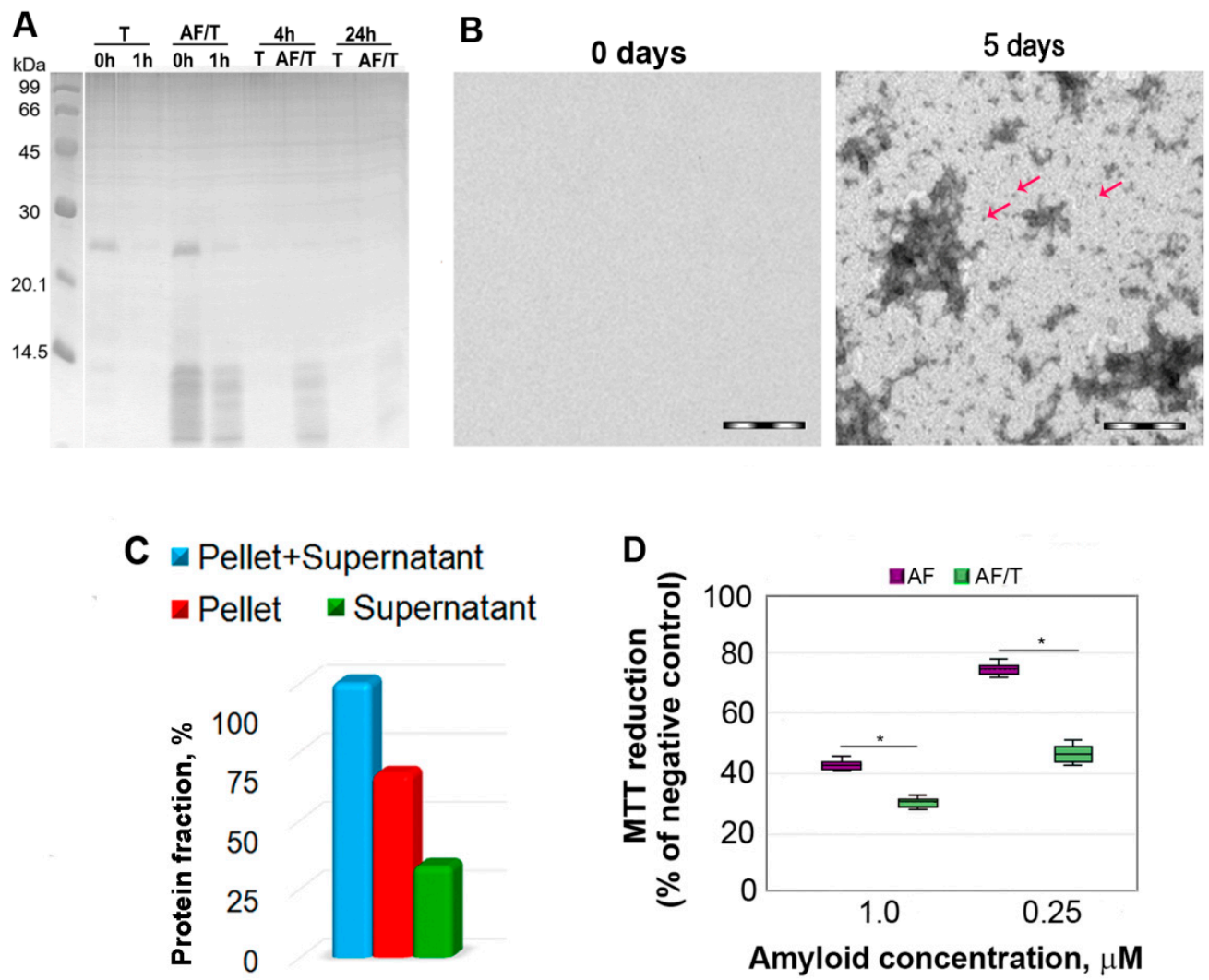

Figure 6. Stability and inhibitory effect on cells of exposed to trypsin amyloid fibrils formed from beta-2-microglobulin $(\beta 2 \mathrm{M})$ at $\mathrm{pH}$ 2. (A) Trypsin-induced degradation of beta-2-microglobulin amyloid fibrils detected by SDS-PAGE under denaturing conditions. The amyloid fibrils after adding trypsin (AF/T) and trypsin (T) solutions were incubated in PBS at $37^{\circ} \mathrm{C}$, and aliquots were taken at different time points. Molecular weight of beta-2-microglobulin and trypsin is 11.8 and $23.3 \mathrm{kDa}$, respectively. (B) The electron micrographs of supernatant collected by centrifugation of amyloid fibrils before and five days after adding trypsin. Scale bars are equal to $200 \mathrm{~nm}$. The estimated size of aggregates corresponds to 20 (shown by red arrows) or more monomeric protein molecules as evaluated by ImageJ. (C) Redistribution of the protein between supernatant and pellet obtained by centrifugation of amyloid fibrils treated with trypsin. (D) Dose-dependent inhibition effect of amyloid fibrils on HeLa cells determined by MTT assay. Cells were exposed to amyloid fibrils, intact or treated with trypsin (weight ratio of fibrils to trypsin was kept at 7.5/1), at indicated concentrations for $24 \mathrm{~h}$. Data are expressed as medians and interquartile ranges, whiskers denote $1.5 \times$ IQR. Experiments were repeated at least three times with similar results. ANOVA, Tukey post hoc test, ${ }^{*} p<0.01$.

SDS-PAGE of amyloid fibrils formed from beta-2-microglobulin untreated with trypsin showed a band with a molecular weight of 23-24 kDa, corresponding to the molecular weight of the dimeric form of the protein (Figure S13). SDS-PAGE of the sample of beta-2microglobulin fibrils mixed with trypsin, the proteolytic activity of which was quenched by PMSF, revealed two separate bands with close molecular weights (about 23-24 kDa), corresponding to the molecular weight of beta-2-microglobulin dimer found in amyloid fibrils untreated with trypsin, and to the molecular weight of trypsin (Figure S13). Beta2-microglobulin dimer exhibited a lower electrophoretic mobility compared to trypsin. SDS-PAGE of amyloid beta-2-microglobulin fibrils treated with trypsin showed a single band with a molecular weight of $23-24 \mathrm{kDa}$ (Figure $6 \mathrm{~A}$ ), corresponding to the molecular weight of trypsin, and not to the dimeric form beta-2-microglobulin (which appears to have been degraded immediately after the addition of trypsin). Thus, in the case of beta-2microglobulin fibrils in contrast to lysozyme fibrils, trypsin can be detected in the sample using SDS-PAGE.

TEM data indicate that, after adding trypsin to the sample, the fibril fragments lose their rigid fiber structure, as in the case of various types of lysozyme amyloid fibrils 
(Figure 5A and Figure S12). This mechanism of trypsin action is also confirmed by a decrease in the fluorescence intensity of ANS (Figure 5I) and ThT (Figure 5H) in the sample. Thus, the mechanism of action of trypsin is not affected by either the morphology or the structure (primary and secondary) of the amyloidogenic protein.

The trypsin-induced change in the fluorescence intensity of the dyes bound to beta-2microglobulin amyloid fibrils (Figure 5H,I), and the decrease in the RLS value measured for them five days after the start of the experiment (Figure 5G) were more pronounced than the change in these characteristics for both types of lysozyme amyloid fibrils (Figure 1G-I and Figure 5G-I). In addition, the proportion of the degraded fraction of fibrils five days after the addition of trypsin in the case of beta-2-microglobulin amyloids (Figures 2A, 4C and 6B) was more than $30 \%$ and was noticeably higher than in the case of both types of lysozyme amyloid fibrils (Figures 2B, 4D and 6C). This indicates that the efficiency of proteolytic degradation of amyloid fibrils depends on the primary structure of the protein.

After treatment of beta-2-microglobulin amyloid fibrils with trypsin, a significant decrease in the values of parameter $A$ (Figure 5E) and fluorescence anisotropy (Figure 5F) was observed, as well as a red shift in the maximum of the fluorescence spectrum of the sample (Figure 5D). In addition, a significant decrease in the integral fluorescence intensity of tryptophan residues of amyloid fibrils (Figure 5C) after adding trypsin was found. The shape of the $\mathrm{CD}$ spectrum of beta-2-microglobulin amyloid fibrils differed from the shape of the CD spectrum of the sample measured $20 \mathrm{~min}$ after adding trypsin (Figure 5B). The change in the shape of the CD spectrum of the sample recorded $24 \mathrm{~h}$ after adding trypsin was even more pronounced. According to the assessment of the content of various types of secondary structure in the samples, the trypsin addition to the studied amyloid fibrils leads to an increase in the proportion of disordered structure due to a decrease in the proportion of $\beta$-strands in the amyloid-forming protein (Figure S9C). The observed changes confirm the assumption about the degradation of amyloid fibrils.

Trypsin can be detected in a sample with beta-2-microglobulin amyloid fibrils no more than a day after its addition by SDS-PAGE (Figure 6A). The most pronounced changes in the photophysical characteristics and morphology of these amyloid fibrils after trypsin adding were observed in the same period (Figure 5). Further moderate changes either may be associated with the immediate action of a small amount of trypsin molecules remaining in the sample, which avoid detection by SDS-PAGE, or may be the result of processes triggered by trypsin on the first day after its addition (leading to the decreased stability of fibrils).

The results obtained in the study of the cytotoxicity of beta-2-microglobulin amyloid fibrils after trypsin addition were quite unexpected. We not only did not observe a decrease but observed an increase in the cytotoxicity of amyloids of this protein after their treatment with trypsin (Figure 6D). It can be assumed that, in the case of beta-2microglobulin fibrils, the cytotoxicity of the forming amyloid aggregates (fragments of amyloid fibrils or non-fibrillar amyloid aggregates) is higher than in the case of amyloid fibrils of lysozyme. Another reason for the observed effect may be the greater number of formed toxic non-fibrillar aggregates (Figure S12) in relation to non-toxic protein monomers and their fragments (Figure S10) than in the case of lysozyme fibrils.

Thus, the results obtained on the example of two amyloidogenic proteins (and three polymorphic structures) made it possible to assume that the mechanism of fibril degradation under the action of trypsin did not depend on the morphology or primary and secondary structure of the amyloidogenic protein. At the same time, the rate of proteolytic degradation of amyloids depends on the morphology and degree of clustering of fibrils. In addition, it was suggested that the cytotoxicity of trypsin-degraded amyloid fibrils might depend on the ratio of highly toxic and low toxic/non-toxic protein species in the sample after such exposure. 


\section{Discussion}

In this study, we demonstrated that the proteolytic enzyme of the pancreas, trypsin, can lead to degradation of amyloid fibrils, which results in fragmentation of their fiber and a decrease in the ordering of amyloid-forming proteins with the formation of non-fibrillar aggregates of various sizes. In this case, trypsin facilitates the degradation of fibrils across the entire length of their fiber rather than starting from the fibril ends, suggesting that proteolysis is not directional. These ideas are in good agreement with the results of the work Chander et al. [19], where through the electron microscopic analysis of immunogold labeling of trypsin binding to $A \beta 40$ and $A \beta 42$, the protease binding to fibrils along the entire length of their fiber and not only to the ends of the fibrils was shown. It should be noted that the mechanism of proteolytic degradation of amyloid fibrils observed by us is similar to that previously proposed by Poepsel et al. [17] in the study of fragmentation of the tau protein fibrils under the action of serine protease HTRA1 (belongs to the high temperature requirement $\mathrm{A}(\mathrm{Htr} \mathrm{A})$ family of serine proteases), implying the universality of protease action. According to the observed degradation mechanism, trypsin can affect both the structure of protein molecules forming $\beta$-sheets and intermolecular hydrogen bonds involved in the formation of amyloid fibers.

Our data for two amyloidogenic proteins (and three polymorphic structures) show the reliance of the effectiveness and rate of trypsin action on amyloid fibrils on the structure of the amyloid-forming protein (primary, secondary, and tertiary), which determines the number and localization of proteolytic cleavage sites, as well as on the morphology and degree of clustering of amyloid fibrils, which determine the availability of trypsin binding sites. This is in line with the literature data [17], indicating that the disintegration activity of HTRA1 significantly increases the rate of proteolytic degradation of densely packed areas of fibrils, which leads to more efficient fragmentation of amyloid fibers.

Binding of proteases to amyloids and proteolytic degradation of fibrils, at first glance, seems to be a positive effect in terms of amyloidosis treatment; however, this is actually not entirely true. The interaction of trypsin with abnormal aggregates amyloid fibrils, which was shown in our work, as well as in the work [19], can lead to the inability of the enzyme interaction with other substrates. For example, trypsin is required for $A \beta-$ peptide catabolism, and its interaction with $A \beta$-peptide amyloids can reduce clearance of soluble $A \beta$-peptide, and an increased concentration of $A \beta$-peptide enhances its aggregation. A similar conclusion was reached in the study of the trypsin binding to fibrillar $A \beta$ peptide [19]. This assumption is also in a good agreement with the results according to which mice deficient of proteolytic enzymes exhibited elevated levels of $A \beta$ while overexpression of neprilysin in APP-transgenic mice could reduce the deposition of fibrillar $\mathrm{A} \beta[62,63]$.

In addition, we showed that proteolytic degradation of amyloids did not reduce cytotoxicity of the protein aggregates for Hela cells, as might be expected. We attribute this to the formation of highly toxic non-fibrillar aggregates along with the formation of nontoxic protein monomers and their fragments induced by trypsin. A high cytotoxicity of large disordered aggregates forming after exposure of the lysozyme and beta-2-microglobulin fibrils to the protein with chaperone activity alpha-B-crystallin was already demonstrated by us earlier [34].

In conclusion, here, we show that the proteolytic enzyme of the pancreas, trypsin, can induce degradation of amyloid fibrils, and the mechanism of this process is qualitatively the same for amyloids with different structure and morphology. At the same time, the efficiency and rate of fibril degradation are dependent on the structure of the amyloidforming protein as well as on the morphology and clustering of amyloid fibrils, which determines the number, localization, and availability of protease cleavage sites. Proteolytic degradation of amyloids not only does not reduce, as might be expected, but, in some cases, even increases cytotoxicity of the amyloid fibrils, presumably due to the formation of more toxic non-fibrillar aggregates. 


\section{Materials and Methods}

\subsection{Materials}

Guanidine hydrochloride (GdnHCl), lysozyme, buffer components, trypsin from bovine pancreas, and 3-(4,5-dimethylthiazol-2-yl)-2,5-diphenyltetrazolium bromide (MTT) were purchased from Sigma (St. Louis, MO, USA). Thioflavin T (ThT) "UltraPure Grade" was supplied by AnaSpec (Fremont, CA, USA), and 8-anilino-1-naphthalene sulfonate (ANS) was from Serva (Heidelberg, Germany). Further purification of chemicals has not been performed. Reagents for cell cultivation, including DMEM medium (glucose $4.5 \mathrm{~g} / \mathrm{L}$ ), fetal bovine serum (FBS), and $0.25 \%$ Trypsin-EDTA were acquired from Gibco (Thermo Fisher Scientific, Waltham, MA, USA). Culture flasks and 96-well plates (flat bottom) were from Corning (New York, NY, USA).

\subsection{Amyloid Fibrils Preparation}

For the preparation of amyloid fibrils from beta-2-microglobulin, the protocol described in the work [64] was used. The samples of recombinant beta-2-microglobulin were received from Mikhail M. Shavlovsky, Dmitry S. Polyakov, and Rodion G. Sakhabeev (Department of Molecular Genetics, Institute of Experimental Medicine). Lysozyme amyloid fibrils were grown under the following conditions: (1) $100 \mathrm{mM} \mathrm{KH}_{2} \mathrm{PO}_{4} / \mathrm{NaOH}(\mathrm{pH} 7)$ supplemented with $3 \mathrm{M} \mathrm{GdnHCl}$ and incubation at $57^{\circ} \mathrm{C}$, and (2) $20 \%$ acetic acid/100 mM $\mathrm{NaCl}(\mathrm{pH} 2)$ and incubation at $37^{\circ} \mathrm{C}$ [30]. The concentration of a protein was $2 \mathrm{mg} / \mathrm{mL}$. Fibrilogenesis was performed with constant agitation for one day (500 rpm). The constant temperature during fibril grows, maintained by the TS-100 Thermo-Shaker (Biosan, Warren, MI, USA). A two-step buffer exchange in mature amyloid fibrils (with deionized water and then with $20 \mathrm{mM}$ sodium phosphate buffer ( $\mathrm{pH}$ 7.4)) was made by dialysis.

\subsection{Amyloid Fibrils Degradation by Trypsin}

The final concentration of fibril used for spectroscopic measurement was $0.15 \mathrm{mg} / \mathrm{mL}$. To avoid autolysis [31,65], trypsin stock was stored frozen in acidic conditions $(1 \mathrm{mM} \mathrm{HCl})$; it was thawed immediately before adding to the fibril solutions (the weight ratio of enzyme to fibrils was 1 to 125 unless otherwise specified). In some cases, the concentration of trypsin was increased so that the ratio of protease to fibril was 1:7.5 and 1:1.

The experiment was initiated by manual mixing of the fibril solutions with protease, and the measurements were carried out within five days. The dead-time of measurements with manual mixing was estimated as $4 \mathrm{~s}$. [38,39] TEM images were acquired at different time points sampling $10 \mu \mathrm{L}$ of fibril/trypsin mixture.

To prepare samples for SDS-PAGE under denaturing conditions, the concentration of amyloid fibrils increased up to $24 \mathrm{mg} / \mathrm{mL}$, and trypsin concentration was $0.4 \mathrm{mg} / \mathrm{mL}$. Thus, the weight ratio of the protease to amyloid fibrils was 1:60. The protease in this concentration can be detectable by $17 \%$ SDS-PAGE. For identification of aggregates formed after treatment of amyloid fibrils with trypsin, we modified the experiment as follows: samples of amyloid fibrils five days after the addition of trypsin in a ratio of 7.5:1 and 1:1 were analyzed using an $8 \%$ polyacrylamide gel.

In the experiments on resistance of the native proteins to proteolytic cleavage by trypsin, the following conditions were used: the concentration of native lysozyme and beta-2-microglobulin was kept at $0.4 \mathrm{mg} / \mathrm{mL}$, and the weight ratio of both proteins to protease was 10:1.

Proteolytic digestion of native bovine serum albumin (BSA) by trypsin was performed at $37^{\circ} \mathrm{C}$. Aliquots of reaction mixture were collected at different times with the addition of phenylmethylsulfonyl fluoride (PMSF) to stop the proteolysis. The concentration BSA was kept at $50 \mathrm{mg} / \mathrm{mL}$, and weight ratio of the protein to protease was 125:1.

\subsection{Transmission Electron Microscopy}

A transmission electron microscope Libra 120 (Carl Zeiss, Oberkochen, Germany) was applied to produce micrograph amyloid fibrils and degraded amyloid aggregates after 
proteases exposure. Samples were put on the cooper grids coated with formvar/carbon films (Electron Microscopy Sciences, Hatfield, PA, USA) and stained by a $1 \%$ aqueous solution of uranyl acetate. TEM images were analyzed using ImageJ software. The number of monomers comprising the aggregates was estimated by their area.

\subsection{Confocal Microscopy}

Confocal laser scanning microscope Olympus FV 3000 (Olympus, Tokyo, Japan) and oil immersion objective with a $60 \times$ magnification, numerical aperture NA 1.42 , and laser with excitation line $405 \mathrm{~nm}$ was applied to reveal the difference in morphology of ThTstained amyloids formed from lysozyme in the different conditions.

\subsection{Spectral Measurements}

The samples prepared according to the Section 4.3 were used for fluorescence studies. A U-3900H spectrophotometer (Hitachi, Tokyo, Japan) was applied to collect the absorption spectra of the samples. The absorption spectra of amyloid fibrils and mixtures of fibrils with ThT or ANS were corrected by the light scattering according to standard procedure [66]. The concentration of ThT and ANS and fibrils from lysozyme and beta-2microglobulin was quantified using molar extinction coefficients of $\varepsilon_{412}=31,600 \mathrm{M}^{-1} \mathrm{~cm}^{-1}$, $\varepsilon_{350}=5000 \mathrm{M}^{-1} \mathrm{~cm}^{-1}, \varepsilon_{280}=36,000 \mathrm{M}^{-1} \mathrm{~cm}^{-1}$, and $\varepsilon_{276}=20,065 \mathrm{M}^{-1} \mathrm{~cm}^{-1}$, respectively. The absorbance of a dye did not exceed 0.5 in experiments with ThT and ANS.

Fluorescence spectra of samples was measured using the Cary Eclipse spectrofluorimeter (Varian, Melbourne, Australia). The parameters of tryptophan fluorescence of the fibrils were recorded using excitation wavelength of $295 \mathrm{~nm}$ and corrected for instrument sensitivity. The change of the position and shape of the fluorescence spectra of fibrils was tested by parameter $A=I_{320} / I_{365}$, with $I_{320}$ and $I_{365}$ being the fluorescence intensities at the emission wavelengths of 320 and $365 \mathrm{~nm}$, respectively [38,39]. The anisotropy of tryptophan fluorescence was calculated by the equation:

$$
r=\frac{\left(I_{V}^{V}-G I_{H}^{V}\right)}{\left(I_{V}^{V}+2 G I_{H}^{V}\right)}
$$

where $I_{V}^{V}$ and $I_{H}^{V}$ are vertical and horizontal components of the fluorescence intensity excited by vertically polarized light and recorded at the wavelength of $365 \mathrm{~nm}$, and $G=I_{V}^{H} / I_{H}^{H}$ is the coefficient that takes into account that instrument sensitivity for the vertical and horizontal components of the fluorescence is different [67]. The size of aggregates in the fibril samples was characterized by Rayleigh light scattering (RLS) recorded using the same wavelength of excitation and registration $(295 \mathrm{~nm})$. Trypsin molecules themselves had a low RLS (close to RLS of buffer solution alone) due to the low concentration of proteases used.

Fluorescence of ThT and ANS was excited at a wavelength of 440 and $350 \mathrm{~nm}$, respectively. The spectral slits width did not exceed $5 \mathrm{~nm}$ in most experiments. Increasing the slit widths did not influence the experimental results. The fluorescence intensity was corrected on the primary inner filter effect [68]. The fluorescence intensity of ThT and ANS in the presence of trypsin without amyloids was equal to that of the dyes buffered solutions and did not contribute to the ThT and ANS intensities during the degradation of amyloid fibrils.

Far-UV CD spectra (190-260 nm) of fibrils were measured using a J-810 spectropolarimeter (Jasco, Tokyo, Japan) equipped with a $1 \mathrm{~mm}$ path length cell. Three scans of CD spectra were averaged and base line corrected, which was achieved using the appropriate buffer. The $\mathrm{CD}$ spectrum of the trypsin in the concentration used matches the signal of the buffer solution alone. CD spectra of fibrils were corrected for CD spectrum of the trypsin. The secondary structure content of fibrils was estimated from their corrected CD spectra, which were used to determine in the CDPro package [58] that incorporates three regression 
methods (Selcon, Contin, and CDSSTR) and several basic sets of proteins (including soluble, membrane, and denatured proteins with a known secondary structure).

\subsection{MTT Assay}

HeLa cells were propagated in DMEM medium supplemented with $10 \% \mathrm{FBS}, 50 \mu \mathrm{g} / \mathrm{mL}$ penicillin-streptomycin, and $2 \mathrm{mM}$ l-glutamine and were grown in a humidified incubator with $5 \% \mathrm{CO}_{2}$ at $37^{\circ} \mathrm{C}$. A day before the MTT assay, confluent HeLa cells were seeded in 96-well coated culture plates at density of 3000 viable cells/well in $120 \mu \mathrm{L}$ of culture medium and were kept at at $37{ }^{\circ} \mathrm{C}$ and $5 \% \mathrm{CO}_{2}$. Amyloid aggregates were added to cells at a final concentration of $0.7 \mu \mathrm{M}$ (lysozyme fibrils) or $1 \mu \mathrm{M}$ (beta-2-microglobulin fibrils). The weight ratio of protein to trypsin was 125:1. Additionally, to enrich the samples of amyloid fibrils with the degraded fraction, for this experiment, we increased the concentration of trypsin 17-fold, so the weight ratio of protein to trypsin was 7.5:1. The same mass ratio of protein and trypsin (7.5:1) was used to obtain fragments of monomeric lysozyme, which was preliminarily boiled for $30 \mathrm{~min}$ to transform the protein (that is highly protease-resistant in native state) into a denatured state. The toxicity of aggregates to cell was evaluated $24 \mathrm{~h}$ after their addition to cells by the MTT (Sigma-Aldrich, St. Louis, MO, USA) reduction inhibition assay according to standard protocol $[69,70]$ using an automatic plate reader (Bio-Rad, Milan, Italy). Cell viability was assessed based on the value of the absorption of MMT dye. The absorption of MMT dye was the average of five independent measurements as corrected for the blank. Recorded data were normalized to the value for controls containing equal amounts of trypsin in amyloid incubation buffer.

\subsection{Statistical Analysis}

The spectral data of fibrils are shown as the mean of at least three independent measurements. The data of MMT assay are demonstrated as the median of three experiments.

Statistical analysis performed using GraphPad Prism (Version 9.1.0) software (GraphPad Software, San Diego, California, USA). The reliability of the results was verified using Student $t$-test for paired measurement and one-way analysis of variance (ANOVA) for unpaired measurement.

Supplementary Materials: The following are available online at https://www.mdpi.com/article/10 .3390/ijms22094828/s1: Figure S1: Autolysis of trypsin in PBS at $37^{\circ} \mathrm{C}$, Figure S2: Trypsin digestion of native bovine serum albumin (BSA), Figure S3: The binding of trypsin to lysozyme amyloid fibrils prepared at $\mathrm{pH} 2$ and pH7, Figure S4: The stability of amyloid fibrils, Figure S5: Redistribution of the protein between supernatant and pellet obtained by centrifugation of amyloid fibrils formed from lysozyme at pH 7 (Lys_AF (pH 7)) and at pH 2 (Lys_AF (pH 2)) treated with trypsin, Figure S6: Trypsin induced degradation of lysozyme amyloid fibrils prepared at pH7, Figure S7: Trypsin digestion of lysozyme and beta-2-microglobulin ( $\beta 2 \mathrm{M})$ in their native state, Figure S8: Spectral characteristics of amyloid fibrils formed from lysozyme at $\mathrm{pH} 7$ and at $\mathrm{pH} 2$ treated with trypsin, Figure S9: Trypsin induced changes of the secondary structure of amyloid fibrils formed from lysozyme at $\mathrm{pH} 7$, lysozyme at $\mathrm{pH} 2$ and beta-2-microglobulin at $\mathrm{pH} 2$, Figure S10: The effect of amyloidogenic proteins and their fragments on the cells determined by MTT assay, Figure S11: Identification of aggregates formed after treatment of amyloid fibrils with trypsin, Figure S12: Characteristics of aggregates formed after treatment of amyloid fibrils with trypsin, Figure S13: SDS-PAGE of beta-2-microglobulin amyloid fibrils mixed with trypsin.

Author Contributions: Conceptualization and supervision: I.M.K., K.K.T., and A.I.S.; methodology: O.V.S. (Olga V. Stepanenko), E.V.M., and A.I.S.; investigation and visualization: O.V.S. (Olga V. Stepanenko), M.I.S., E.V.M., O.V.S. (Olesya V. Stepanenko), and A.I.S.; writing-original draft preparation, review, and editing: O.V.S. (Olga V. Stepanenko), M.I.S., E.V.M., O.V.S. (Olesya V. Stepanenko), I.M.K., K.K.T., and A.I.S. All authors have read and agreed to the published version of the manuscript.

Funding: This work was supported by the Russian Science Foundation (NO. 18-74-10100).

Institutional Review Board Statement: Not applicable.

Informed Consent Statement: Not applicable. 
Acknowledgments: We are grateful to M.M. Shavlovsky, D.S. Polyakov, and R.G. Sakhabeev (Department of Molecular Genetics, Institute of Experimental Medicine, Russia) for the beta-2microglobulin providing.

Conflicts of Interest: The authors declare no conflict of interest. The funders had no role in the design of the study; in the collection, analyses, or interpretation of data; in the writing of the manuscript, or in the decision to publish the results.

\section{References}

1. Merlini, G.; Bellotti, V. Molecular mechanisms of amyloidosis. N. Engl. J. Med. 2003, 349, 583-596. [CrossRef] [PubMed]

2. Recchia, A.; Debetto, P.; Negro, A.; Guidolin, D.; Skaper, S.D.; Giusti, P. Alpha-synuclein and Parkinson's disease. FASEB J. Off. Publ. Fed. Am. Soc. Exp. Biol. 2004, 18, 617-626. [CrossRef]

3. Lu, J.X.; Qiang, W.; Yau, W.M.; Schwieters, C.D.; Meredith, S.C.; Tycko, R. Molecular structure of beta-amyloid fibrils in Alzheimer's disease brain tissue. Cell 2013, 154, 1257-1268. [CrossRef] [PubMed]

4. Naiki, H.; Okoshi, T.; Ozawa, D.; Yamaguchi, I.; Hasegawa, K. Molecular pathogenesis of human amyloidosis: Lessons from beta2 -microglobulin-related amyloidosis. Pathol. Int. 2016, 66, 193-201. [CrossRef] [PubMed]

5. Sipe, J.D.; Benson, M.D.; Buxbaum, J.N.; Ikeda, S.I.; Merlini, G.; Saraiva, M.J.; Westermark, P. Amyloid fibril proteins and amyloidosis: Chemical identification and clinical classification International Society of Amyloidosis 2016 Nomenclature Guidelines. Amyloid Int. J. Exp. Clin. Investig. Off. J. Int. Soc. Amyloidosis 2016, 23, 209-213. [CrossRef] [PubMed]

6. Esposito, G.; Michelutti, R.; Verdone, G.; Viglino, P.; Hernandez, H.; Robinson, C.V.; Amoresano, A.; Dal Piaz, F.; Monti, M.; Pucci, P.; et al. Removal of the N-terminal hexapeptide from human beta2-microglobulin facilitates protein aggregation and fibril formation. Protein Sci. A Publ. Protein Soc. 2000, 9, 831-845. [CrossRef] [PubMed]

7. Sattianayagam, P.T.; Gibbs, S.D.; Rowczenio, D.; Pinney, J.H.; Wechalekar, A.D.; Gilbertson, J.A.; Hawkins, P.N.; Lachmann, H.J.; Gillmore, J.D. Hereditary lysozyme amyloidosis-phenotypic heterogeneity and the role of solid organ transplantation. J. Intern. Med. 2012, 272, 36-44. [CrossRef]

8. Wilquet, V.; De Strooper, B. Amyloid-beta precursor protein processing in neurodegeneration. Curr. Opin. Neurobiol. 2004, 14, 582-588. [CrossRef] [PubMed]

9. Gebbink, M.F.; Voest, E.E.; Reijerkerk, A. Do antiangiogenic protein fragments have amyloid properties? Blood 2004, 104, 1601-1605. [CrossRef]

10. Zhang, H.; Ma, Q.; Zhang, Y.W.; Xu, H. Proteolytic processing of Alzheimer's beta-amyloid precursor protein. J. Neurochem. 2012, 120, 9-21. [CrossRef]

11. Hogl, S.; Kuhn, P.H.; Colombo, A.; Lichtenthaler, S.F. Determination of the proteolytic cleavage sites of the amyloid precursor-like protein 2 by the proteases ADAM10, BACE1 and gamma-secretase. PLoS ONE 2011, 6, e21337. [CrossRef] [PubMed]

12. Mirgorodskaia, O.A.; Kazanina, G.A.; Mirgorodskaia, E.P.; Shevchenko, A.A.; Mal'tsev, K.V.; Miroshnikov, A.I.; Roipstorff, P. Proteolysis of human proinsulin catalysed by native, modified, and immobilized trypsin. Bioorg. Khimiia 1997, $23,91-97$.

13. Gao, Y.Z.; Xu, H.H.; Ju, T.T.; Zhao, X.H. The effect of limited proteolysis by different proteases on the formation of whey protein fibrils. J. Dairy Sci. 2013, 96, 7383-7392. [CrossRef]

14. Mangione, P.P.; Porcari, R.; Gillmore, J.D.; Pucci, P.; Monti, M.; Porcari, M.; Giorgetti, S.; Marchese, L.; Raimondi, S.; Serpell, L.C.; et al. Proteolytic cleavage of Ser52Pro variant transthyretin triggers its amyloid fibrillogenesis. Proc. Natl. Acad. Sci. USA 2014, 111, 1539-1544. [CrossRef] [PubMed]

15. Marcoux, J.; Mangione, P.P.; Porcari, R.; Degiacomi, M.T.; Verona, G.; Taylor, G.W.; Giorgetti, S.; Raimondi, S.; Sanglier-Cianferani, S.; Benesch, J.L.; et al. A novel mechano-enzymatic cleavage mechanism underlies transthyretin amyloidogenesis. EMBO Mol. Med. 2015, 7, 1337-1349. [CrossRef] [PubMed]

16. Shin, T.M.; Isas, J.M.; Hsieh, C.L.; Kayed, R.; Glabe, C.G.; Langen, R.; Chen, J. Formation of soluble amyloid oligomers and amyloid fibrils by the multifunctional protein vitronectin. Mol. Neurodegener. 2008, 3, 16. [CrossRef]

17. Poepsel, S.; Sprengel, A.; Sacca, B.; Kaschani, F.; Kaiser, M.; Gatsogiannis, C.; Raunser, S.; Clausen, T.; Ehrmann, M. Determinants of amyloid fibril degradation by the PDZ protease HTRA1. Nat. Chem. Biol. 2015, 11, 862-869. [CrossRef] [PubMed]

18. Soderberg, L.; Dahlqvist, C.; Kakuyama, H.; Thyberg, J.; Ito, A.; Winblad, B.; Naslund, J.; Tjernberg, L.O. Collagenous Alzheimer amyloid plaque component assembles amyloid fibrils into protease resistant aggregates. FEBS J. 2005, 272, 2231-2236. [CrossRef]

19. Chander, H.; Chauhan, A.; Wegiel, J.; Malik, M.; Sheikh, A.; Chauhan, V. Binding of trypsin to fibrillar amyloid beta-protein. Brain Res. 2006, 1082, 173-181. [CrossRef]

20. Azevedo, E.P.; Guimaraes-Costa, A.B.; Torezani, G.S.; Braga, C.A.; Palhano, F.L.; Kelly, J.W.; Saraiva, E.M.; Foguel, D. Amyloid fibrils trigger the release of neutrophil extracellular traps (NETs), causing fibril fragmentation by NET-associated elastase. J. Biol. Chem. 2012, 287, 37206-37218. [CrossRef]

21. Emeson, E.E.; Kikkawa, Y.; Gueft, B. New features of amyloid found after digestion with trypsin. J. Cell Biol. 1966, $28,570-577$. [CrossRef]

22. Bezawork-Geleta, A.; Brodie, E.J.; Dougan, D.A.; Truscott, K.N. LON is the master protease that protects against protein aggregation in human mitochondria through direct degradation of misfolded proteins. Sci. Rep. 2015, 5, 17397. [CrossRef] [PubMed] 
23. Wagner, I.; Arlt, H.; van Dyck, L.; Langer, T.; Neupert, W. Molecular chaperones cooperate with PIM1 protease in the degradation of misfolded proteins in mitochondria. EMBO J. 1994, 13, 5135-5145. [CrossRef] [PubMed]

24. Ninagawa, S.; Mori, K. Trypsin Sensitivity Assay to Study the Folding Status of Proteins. BIO-PROTOCOL 2016, 6. [CrossRef]

25. Kay, J. A possible role for neutral proteolysis in the degradation of intracellular proteins. Ciba Found. Symp. 1979, 219-225. [CrossRef]

26. Sanchez-Ruiz, J.M. Protein kinetic stability. Biophys. Chem. 2010, 148, 1-15. [CrossRef]

27. Merulla, J.; Fasana, E.; Solda, T.; Molinari, M. Specificity and regulation of the endoplasmic reticulum-associated degradation machinery. Traffic 2013, 14, 767-777. [CrossRef]

28. Pleyer, C.; Flesche, J.; Saeed, F. Lysozyme amyloidosis-a case report and review of the literature. Clin. Nephrol. Case Stud. 2015, 3, 42-45. [CrossRef]

29. Scarpioni, R.; Ricardi, M.; Albertazzi, V.; De Amicis, S.; Rastelli, F.; Zerbini, L. Dialysis-related amyloidosis: Challenges and solutions. Int. J. Nephrol. Renov. Dis. 2016, 9, 319-328. [CrossRef]

30. Sulatskaya, A.I.; Rodina, N.P.; Kuznetsova, I.M.; Turoverov, K.K. Different conditions of fibrillogenesis cause polymorphysm of lysozyme amyloid fibrils. J. Mol. Struct. 2017, 1140, 52-58. [CrossRef]

31. Sipos, T.; Merkel, J.R. An effect of calcium ions on the activity, heat stability, and structure of trypsin. Biochemistry 1970, 9 , 2766-2775. [CrossRef]

32. Kolodzeiskaia, M.V. Serine proteinases of lower vertebrates. Ukr. Biokhimicheskii Zhurnal 1986, 58, 90-104.

33. Buck, F.F.; Vithayathil, A.J.; Bier, M.; Nord, F.F. On the mechanism of enzyme action. 73. Studies on trypsins from beef, sheep and pig pancreas. Arch. Biochem. Biophys. 1962, 97, 417-424. [CrossRef]

34. Stepanenko, O.V.; Sulatsky, M.I.; Mikhailova, E.V.; Stepanenko, O.V.; Povarova, O.I.; Kuznetsova, I.M.; Turoverov, K.K.; Sulatskaya, A.I. Alpha-B-Crystallin Effect on Mature Amyloid Fibrils: Different Degradation Mechanisms and Changes in Cytotoxicity. Int. J. Mol. Sci. 2020, 21, 7659. [CrossRef] [PubMed]

35. Myers, S.L.; Thomson, N.H.; Radford, S.E.; Ashcroft, A.E. Investigating the structural properties of amyloid-like fibrils formed in vitro from beta2-microglobulin using limited proteolysis and electrospray ionisation mass spectrometry. Rapid Commun. Mass Spectrom. RCM 2006, 20, 1628-1636. [CrossRef]

36. Monti, M.; Amoresano, A.; Giorgetti, S.; Bellotti, V.; Pucci, P. Limited proteolysis in the investigation of beta2-microglobulin amyloidogenic and fibrillar states. Biochim. Biophys. Acta 2005, 1753, 44-50. [CrossRef]

37. Relini, A.; De Stefano, S.; Torrassa, S.; Cavalleri, O.; Rolandi, R.; Gliozzi, A.; Giorgetti, S.; Raimondi, S.; Marchese, L.; Verga, L.; et al. Heparin strongly enhances the formation of beta2-microglobulin amyloid fibrils in the presence of type I collagen. J. Biol. Chem. 2008, 283, 4912-4920. [CrossRef]

38. Turoverov, K.K.; Verkhusha, V.V.; Shavlovsky, M.M.; Biktashev, A.G.; Povarova, O.I.; Kuznetsova, I.M. Kinetics of actin unfolding induced by guanidine hydrochloride. Biochemistry 2002, 41, 1014-1019. [CrossRef]

39. Kuznetsova, I.M.; Stepanenko, O.V.; Stepanenko, O.V.; Povarova, O.I.; Biktashev, A.G.; Verkhusha, V.V.; Shavlovsky, M.M.; Turoverov, K.K. The place of inactivated actin and its kinetic predecessor in actin folding-unfolding. Biochemistry 2002, 41, 13127-13132. [CrossRef]

40. Mine, Y.; Ma, F.; Lauriau, S. Antimicrobial peptides released by enzymatic hydrolysis of hen egg white lysozyme. J. Agric. Food Chem. 2004, 52, 1088-1094. [CrossRef]

41. Proctor, V.A.; Cunningham, F.E. The chemistry of lysozyme and its use as a food preservative and a pharmaceutical. Crit. Rev. Food Sci. Nutr. 1988, 26, 359-395. [CrossRef] [PubMed]

42. Naiki, H.; Higuchi, K.; Hosokawa, M.; Takeda, T. Fluorometric determination of amyloid fibrils in vitro using the fluorescent dye, thioflavin T1. Anal. Biochem. 1989, 177, 244-249. [CrossRef]

43. LeVine, H., 3rd. Quantification of beta-sheet amyloid fibril structures with thioflavin T. Methods Enzym. 1999, 309, 274-284.

44. LeVine, H., 3rd. Thioflavine T interaction with synthetic Alzheimer's disease beta-amyloid peptides: Detection of amyloid aggregation in solution. Protein Sci. 1993, 2, 404-410. [CrossRef]

45. Hawe, A.; Sutter, M.; Jiskoot, W. Extrinsic fluorescent dyes as tools for protein characterization. Pharm. Res. 2008, 25, 1487-1499. [CrossRef]

46. Lindgren, M.; Sorgjerd, K.; Hammarstrom, P. Detection and characterization of aggregates, prefibrillar amyloidogenic oligomers, and protofibrils using fluorescence spectroscopy. Biophys. J. 2005, 88, 4200-4212. [CrossRef]

47. Kuznetsova, I.M.; Sulatskaya, A.I.; Povarova, O.I.; Turoverov, K.K. Reevaluation of ANS binding to human and bovine serum albumins: Key role of equilibrium microdialysis in ligand-receptor binding characterization. PLoS ONE 2012, 7, e40845. [CrossRef]

48. Sulatsky, M.I.; Sulatskaya, A.I.; Povarova, O.I.; Antifeeva, I.A.; Kuznetsova, I.M.; Turoverov, K.K. Effect of the fluorescent probes ThT and ANS on the mature amyloid fibrils. Prion 2020, 14, 67-75. [CrossRef]

49. Sulatsky, M.I.; Sulatskaya, A.I.; Stepanenko, O.V.; Povarova, O.I.; Kuznetsova, I.M.; Turoverov, K.K. Denaturant effect on amyloid fibrils: Declasterization, depolymerization, denaturation and reassembly. Int. J. Biol. Macromol. 2020, 150, 681-694. [CrossRef]

50. Lindberg, D.J.; Wranne, M.S.; Gilbert Gatty, M.; Westerlund, F.; Esbjorner, E.K. Steady-state and time-resolved Thioflavin-T fluorescence can report on morphological differences in amyloid fibrils formed by Abeta(1-40) and Abeta(1-42). Biochem. Biophys. Res. Commun. 2015, 458, 418-423. [CrossRef] 
51. Sidhu, A.; Vaneyck, J.; Blum, C.; Segers-Nolten, I.; Subramaniam, V. Polymorph-specific distribution of binding sites determines thioflavin-T fluorescence intensity in alpha-synuclein fibrils. Amyloid Int. J. Exp. Clin. Investig. Off. J. Int. Soc. Amyloidosis 2018, 25, 189-196. [CrossRef]

52. Stepanenko, O.V.; Povarova, O.I.; Sulatskaya, A.I.; Ferreira, L.A.; Zaslavsky, B.Y.; Kuznetsova, I.M.; Turoverov, K.K.; Uversky, V.N. Protein unfolding in crowded milieu: What crowding can do to a protein undergoing unfolding? J. Biomol. Struct. Dyn. 2016, 34, 2155-2170. [CrossRef] [PubMed]

53. Kuznetsova, I.M.; Stepanenko, O.V.; Turoverov, K.K.; Zhu, L.; Zhou, J.M.; Fink, A.L.; Uversky, V.N. Unraveling multistate unfolding of rabbit muscle creatine kinase. Biochim. Biophys. Acta 2002, 1596, 138-155. [CrossRef]

54. Stepanenko, O.V.; Kuznetsova, I.M.; Turoverov, K.K.; Huang, C.; Wang, C.C. Conformational change of the dimeric DsbC molecule induced by GdnHCl. A study by intrinsic fluorescence. Biochemistry 2004, 43, 5296-5303. [CrossRef]

55. Staiano, M.; D’Auria, S.; Varriale, A.; Rossi, M.; Marabotti, A.; Fini, C.; Stepanenko, O.V.; Kuznetsova, I.M.; Turoverov, K.K. Stability and dynamics of the porcine odorant-binding protein. Biochemistry 2007, 46, 11120-11127. [CrossRef]

56. Staiano, M.; Scognamiglio, V.; Rossi, M.; D’Auria, S.; Stepanenko, O.V.; Kuznetsova, I.M.; Turoverov, K.K. Unfolding and refolding of the glutamine-binding protein from Escherichia coli and its complex with glutamine induced by guanidine hydrochloride. Biochemistry 2005, 44, 5625-5633. [CrossRef]

57. Stepanenko, O.V.; Stepanenko, O.V.; Kuznetsova, I.M.; Shcherbakova, D.M.; Verkhusha, V.V.; Turoverov, K.K. Distinct effects of guanidine thiocyanate on the structure of superfolder GFP. PLoS ONE 2012, 7, e48809. [CrossRef]

58. Sreerama, N.; Woody, R.W. Estimation of protein secondary structure from circular dichroism spectra: Comparison of CONTIN, SELCON, and CDSSTR methods with an expanded reference set. Anal. Biochem. 2000, 287, 252-260. [CrossRef]

59. Krebs, M.R.; Bromley, E.H.; Donald, A.M. The binding of thioflavin-T to amyloid fibrils: Localisation and implications. J. Struct. Biol. 2005, 149, 30-37. [CrossRef] [PubMed]

60. Bolognesi, B.; Kumita, J.R.; Barros, T.P.; Esbjorner, E.K.; Luheshi, L.M.; Crowther, D.C.; Wilson, M.R.; Dobson, C.M.; Favrin, G.; Yerbury, J.J. ANS binding reveals common features of cytotoxic amyloid species. ACS Chem. Biol. 2010, 5, 735-740. [CrossRef] [PubMed]

61. Yanushevich, Y.G.; Staroverov, D.B.; Savitsky, A.P.; Fradkov, A.F.; Gurskaya, N.G.; Bulina, M.E.; Lukyanov, K.A.; Lukyanov, S.A. A strategy for the generation of non-aggregating mutants of Anthozoa fluorescent proteins. FEBS Lett. 2002, 511, 11-14. [CrossRef]

62. Leissring, M.A.; Farris, W.; Chang, A.Y.; Walsh, D.M.; Wu, X.; Sun, X.; Frosch, M.P.; Selkoe, D.J. Enhanced proteolysis of beta-amyloid in APP transgenic mice prevents plaque formation, secondary pathology, and premature death. Neuron 2003, 40, 1087-1093. [CrossRef]

63. Marr, R.A.; Rockenstein, E.; Mukherjee, A.; Kindy, M.S.; Hersh, L.B.; Gage, F.H.; Verma, I.M.; Masliah, E. Neprilysin gene transfer reduces human amyloid pathology in transgenic mice. J. Neurosci. Off. J. Soc. Neurosci. 2003, 23, 1992-1996. [CrossRef]

64. Sulatskaya, A.I.; Rodina, N.P.; Polyakov, D.S.; Sulatsky, M.I.; Artamonova, T.O.; Khodorkovskii, M.A.; Shavlovsky, M.M.; Kuznetsova, I.M.; Turoverov, K.K. Structural Features of Amyloid Fibrils Formed from the Full-Length and Truncated Forms of Beta-2-Microglobulin Probed by Fluorescent Dye Thioflavin T. Int. J. Mol. Sci. 2018, 19, 2762. [CrossRef]

65. Walsh, K.A. Trypsinogens and trypsins of various species. Methods Enzymol. 1970, 19, 41-63. [CrossRef]

66. Vladimirov, Y.A.; Litvin, F.F. Photobiology and spectroscopic methods. In Handbook of General Biophisics; High School: Moscow, Russia, 1964.

67. Turoverov, K.K.; Biktashev, A.G.; Dorofeiuk, A.V.; Kuznetsova, I.M. A complex of apparatus and programs for the measurement of spectral, polarization and kinetic characteristics of fluorescence in solution. Tsitologiia 1998, 40, 806-817.

68. Fonin, A.V.; Sulatskaya, A.I.; Kuznetsova, I.M.; Turoverov, K.K. Fluorescence of dyes in solutions with high absorbance. Inner filter effect correction. PLoS ONE 2014, 9, e103878. [CrossRef]

69. Mosmann, T. Rapid colorimetric assay for cellular growth and survival: Application to proliferation and cytotoxicity assays. J. Immunol. Methods 1983, 65, 55-63. [CrossRef]

70. Nishimura, S.; Murasugi, T.; Kubo, T.; Kaneko, I.; Meguro, M.; Marumoto, S.; Kogen, H.; Koyama, K.; Oda, T.; Nakagami, Y. RS-4252 inhibits amyloid beta-induced cytotoxicity in HeLa cells. Pharmacol. Toxicol. 2003, 93, 29-32. [CrossRef] 